\title{
Cerebral white matter changes
}

Differentiating vascular and degenerative cognitive impairment

$$
\text { by }
$$

Vidar Tveit Vasfaret Stenset

Department of Neurology

Akershus University Hospital

and

Faculty Divison Akershus University Hospital

University of Oslo

2009 
(C) Vidar Tveit Vasfaret Stenset, 2009

Series of dissertations submitted to the

Faculty of Medicine, University of Oslo

No. 873

ISBN 978-82-8072-359-8

All rights reserved. No part of this publication may be

reproduced or transmitted, in any form or by any means, without permission.

Cover: Inger Sandved Anfinsen.

Printed in Norway: AiT e-dit AS, Oslo, 2009.

Produced in co-operation with Unipub AS.

The thesis is produced by Unipub AS merely in connection with the thesis defence. Kindly direct all inquiries regarding the thesis to the copyright holder or the unit which grants the doctorate.

Unipub AS is owned by

The University Foundation for Student Life (SiO) 
In memory of

Petter André 

"Clap your hands and move your feet to the rhythm of the beat"

Dr. Johann Wasmaier 


\section{CONTENTS}

Acknowledgements

List of publications

1. Introduction

1.1 Leukoaraiosis 2

1.1.1 Background 2

1.1.2 Etiology 2

1.1.3 Quantification of white matter lesions 3

1.2 Cognitive Impairment 4

1.2.1 Mild Cognitive Impairment (MCI) 4

1.2.2 The Neurobehavioral Cognitive Status Examination (Cognistat) 5

1.3 Alzheimers disease $\quad 5$

1.3.1 Background $\quad 5$

$\begin{array}{ll}\text { 1.3.2 Alzheimers disease and white matter changes } & 7\end{array}$

1.4 White matter changes and cognition 9

$\begin{array}{lr}1.5 \text { Cerebrospinal fluid markers } & 10\end{array}$

$\begin{array}{ll}1.6 \text { Apolipoprotein E } & 11\end{array}$

$\begin{array}{ll}1.7 \text { Diffusion Tensor Imaging } & 12\end{array}$

$\begin{array}{ll}\text { 1.7.1 General background } & 12\end{array}$

$\begin{array}{ll}\text { 1.7.2 Regions of interest (ROI) analysis } & 13\end{array}$ 
4. General discussion

5. Conclusions and further perspectives

6. References

Errata

Papers I - V 


\section{ACKNOWLEDGEMENTS}

The present work was carried out at the Department of Neurology, Akershus University Hospital in the period 2005 to 2008 with grants from Helse Sør-Øst.

I would like to express my deepest gratitude to my main supervisor, Professor Tormod Fladby, for your unique enthusiasm and valuable discussions. Thank you for sharing your knowledge and being encouraging. Without your good leadership this would never have been possible. When this is over, I'll buy you a beer at "The Bitter End".

I am indebted to my co-supervisor, Professor Leif Gjerstad, for your support and engagement. Your experience and advice have been indispensable.

A big thanks to my former colleagues at the Department of Neurology, Akershus University Hospital and to all co-authors for your help, support, and constructive criticism. A special thanks to all at the Memory Unit for your help with the clinical work up of the patients, and to the girls at the lab for filling in the blanks.

Dag Hofoss - the man of statistics. No problems, only solutions! Lisbeth Johnsen everything under control! Audun E Berstad and Anne Negård - the radiologists who spent hours with me looking at brain scans. I hope you don't dream about WMLs! Anders Skinningsrud - the king of CSF! Atle Bjørnerud - brain imaging personalized! Kristine B Walhovd and Anders M Fjell - WOW! How do you do it? Thanks also to Paulina Due-Tønnessen, Anders Wallin, Pål Gulbrandsen, Ivar Reinvang, and Ramune Grambaite - I have so much to learn from all of you!

I would also like to thank Sissel Reinlie and my new colleagues at the Department of Neurosurgery, Oslo University Hospital Ullevål, for encouragement and time to finish my dissertation.

At last, warm thanks to Lena - the woman of my life, Egil and Sigrunn - my wonderful parents, Eva-Charlotte - my close-to-famous sister, and to all close friends. Thanks for your love and support! 


\section{LIST OF PUBLICATIONS}

I. Stenset V, Johnsen L, Kocot D, Negaard A, Skinningsrud A, Gulbrandsen P, Wallin A, Fladby T. Associations between white matter lesions, cerebrovascular risk factors, and low CSF A $\beta 42$. Neurology 2006;67(5):830833.

II. Stenset V, Hofoss D, Johnsen L, Skinningsrud A, Berstad AE, Negaard A, Reinvang I, Gjerstad L, Fladby T. White matter lesion severity is associated with reduced cognitive performances in patients with normal CSF A $\beta 42$ levels. Acta Neurol Scand. 2008 Dec;118(6):373-378.

III. Stenset V, Hofoss D, Berstad AE, Negaard A, Gjerstad L, Fladby T. White Matter Lesion Subtypes and Cognitive Deficits in Patients with Memory Impairment. Dement Geriatr Cogn Disord 2008;26(5):424-431.

IV. Stenset V, Hofoss D, Johnsen L, Berstad AE, Negaard A, Skinningsrud A, Gjerstad L, Fladby T. White matter lesion load increases the risk of low CSF $\mathrm{A} \beta 42$ in apolipoprotein $\mathrm{E} \varepsilon 4$ carriers. Under review.

V. Stenset V, Bjørnerud A, Fjell AM, Walhovd KB, Hofoss D, Due-Tønnessen P, Gjerstad L, Fladby T. Cingulum fiber diffusivity and CSF T-tau in patients with subjective and mild cognitive impairment. Neurobiol Aging 2009; doi:10.1016/j.neurobiolaging.2009.04.014 (Epub ahead of print) 



\section{INTRODUCTION}

"Dementia is a syndrome due to disease of the brain, usually of a chronic or progressive nature, in which there is disturbance of multiple higher cortical functions, including memory, thinking, orientation, comprehension, calculation, learning capacity, language, and judgement. Consciousness is not clouded. The impairments of cognitive function are commonly accompanied, and occasionally preceded, by deterioration in emotional control, social behaviour, or motivation. This syndrome occurs in Alzheimer's disease, in cerebrovascular disease, and in other conditions primarily or secondarily affecting the brain."

(World Health Organization ICD-10, 2007)

Different types of dementia are difficult to identify in vivo, especially at early stages and partly due to the frequent co-existence of various etiologies. Recent techniques, including examination of biomarkers in cerebrospinal fluid (CSF) and advanced brain imaging techniques facilitate a more precise diagnosis of a given type of dementia. As previous diagnostic criteria for the Alzheimer type of dementia (AD) only captured the disease after dementia occured, new criteria involving recent biomarkers aim to arrive at a diagnosis at early stages, even prior to the onset of overt dementia. Along with episodic memory impairment, neuroimaging and CSF analysis have been proposed as reliable and important tools to make an accurate AD diagnosis possible, including forms of $\mathrm{AD}$ with co-existing cerebrovascular disease.

The objective of this thesis aims to exploit the posssibilities of CSF analysis and neuroimaging in order to better understand the relationship between cerebrovascular and degenerative changes and cognition. To do so, measures of cerebral white matter changes from magnetic resonance imaging (MRI) and diffusion tensor imaging (DTI) were studied in cognitively impaired patients and compared to levels of CSF biomarkers and cognition. In degenerative and vascular cognitive impairment, risk factors and pathological disease processes have been well mapped. However, it remains unclear which exact mechanisms trigger these processes and in which way white matter changes and cortical events are connected. Improved early diagnostic specificity and better knowledge of interaction between vascular and degenerative changes may give rise to specific approaches to prevention and therapy, based upon individual risk-profiles. 


\subsection{Leukoaraiosis}

\subsubsection{Background}

The increased availability of computer tomography (CT) and MRI in clinical practice beginning in the 1970's and 1980's revealed cerebral white matter changes in both normal elderly and cognitively impaired individuals (Verny et al., 1991; Meyer et al., 1992). The observed white matter changes (presenting as diffuse low density areas on CT scans and as areas of hyperintensity on T2- and FLAIR-weighted MRI scans) were often considered to be an expression of leukoencephalopathy associated with Binswanger`s disease (Hachinski et al., 1987; Inzitari and Mascalchi, 1990; O'Sullivan, 2008). In the need for a more neutral term, Hachinski and colleagues suggested the term Leuko-araiosis (leuko $=$ white, araiosis $=$ rarefaction) on the basis of Greek etymology (Hachinski et al., 1987). It was suggested to avoid the term "Binswanger" when describing these white matter rarefactions (Pantoni and Garcia, 1995). White matter changes (WMC), white matter hyperintensities (WMH), and white matter lesions (WML) are now commonly used terms.

\subsubsection{Etiology}

Periventricular and deep white matter areas are supplied by long penetrating arterioles originating from pial arteries (De Reuck, 1971; Salamon et al., 1966). WML in the elderly are associated with microvascular disease leading to ischemia and hypoperfusion (Fernando et al., 2006; Roman et al., 2002; Ward and Brown, 2002). Age, hypertension, and hyperhomocysteinemia are known risk factors for both arteriolosclerosis and WML (Bertsch et al., 2001; Breteler et al., 1994; Vermeer et al., 2002) and post mortem pathological associations between WML and arteriolosclerosis have been described (Awad et al., 1986; van Swieten et al., 1991). There is a strong correlation between age-related WML and vascular risk factors (de Leeuw et al., 2002). In most patients, cognitive impairment associated with WML is regarded primarily as a vascular cognitive disorder (Roman, 2002; Roman et al., 2004).

WML may affect both periventricular (PV) and subcortical (SC) white matter (de Groot et al., 2000a; Fazekas et al., 1993), with PV regions lying in the distal part of the perfused region. Ischemic WML may therefore develop as a result of ischemia caused by arteriolosclerosis, which starts distally in deep penetrating end arterioles as 
suggested by post-mortem studies (De Reuck, 1971; Englund, 2002; Pantoni, 2002; Roman et al., 2002; van Swieten et al., 1991; Simpson et al., 2007).

SC and PV WML subtypes show many similarities with regard to pathogenesis, but substantial differences in tissue response and vascular risk factors between WML in the two regions have been described (Simpson et al., 2007; Lazarus et al., 2005). However, the strong correlation between PV and SC WML suggests etiopathological similarities, implying that these lesions may be manifestations of a single underlying disease process. In this view, PV and SC WML may represent a continuum of neurovascular pathology (DeCarli et al., 2005).

Alternative mechanisms for WML development cannot be excluded. WML have been related to gliosis, demyelination and axonal loss (Awad et al., 1986; Fazekas et al., 1993; van Swieten et al., 1991; Ward and Brown 2002, see below), and genetic factors may also have a strong influence on the development of leukoaraiosis. A study quantifying leukoaraiosis in monozygotic and dizygotic twins suggested that as much as $71 \%$ of the cerebral white matter lesion volume could be explained by heritability (Carmelli et al., 1998). Genes affecting blood pressure or other (metabolic) pathways have been proposed as possible contributors (Turner and Fornage, 2002).

In addition to reduced cognitive function, white matter lesions have been associated with depression, gait disturbances and disability in the elderly (de Groot et al., 2000b; Pantoni et al., 2006; Teodorczuk et al., 2007; Baezner et al., 2008)

\subsubsection{Quantification of white matter lesions}

Several semi-quantitative visual rating scales are available for the grading of white matter lesion severity. Some scales differentiate only into normal, moderate, and severe WML load (van Swieten et al., 1991), while others divide WML into periventricular and subcortical, as well as into different anatomical regions (de Groot et al., 2000a; Fazekas et al., 1987; Scheltens et al., 1993;Wahlund et al., 2001). Other methods include semi-automated volumetric approaches as well as computerassisted volumetric measurements and segmentation methods (DeCarli et al., 1995; Gurol et al., 2006). These various approaches have in common that they measure white matter damage as seen on CT or conventional MRI scans. As WML may be associated with white matter affection beyond lesions visible on conventional MRI (Taylor et al., 2007, O'Sullivan et al., 2001), these commonly used methods may not 
adequately reveal the underlying but visually hidden white matter pathology.

\subsection{Cognitive Impairment}

\subsubsection{Mild Cognitive Impairment (MCI)}

Individuals with cognitive impairment but preserved performance of activities of daily living who do not meet criteria for overt dementia are referred to as patients with mild cognitive impairment (MCI) (Petersen et al., 2001; Petersen et al., 1999). According to the original criteria (Peterson et al., 1999), besides subjective memory impairment, preserved general intellectual function, intact ADL, and absence of overt dementia, objective memory impairment must be present to meet the diagnostic criteria for MCI (amnestic MCI). In the recently revised MCI criteria (Winblad, et al., 2004) also patients without memory impairment, but with deficits in other cognitive domains may be classified as MCI (non-amnestic MCI). In particular patients with amnestic MCI are at risk of developing $\mathrm{AD}$, and 40-60\% will convert to $\mathrm{AD}$ within 5 years (Petersen et al., 2004). MCI etiology clearly is heterogeneous. In order to understand pathogenetic mechanisms and in order to enable development of disease modifying drugs it is important to recognize the underlying pathology at an early stage (DeKosky and Marek, 2003).

Structural and functional imaging studies have revealed alterations of the posterior cortex including posterior cingulate gyrus and the medial temporal lobe (MTL) in patients with MCI and AD. Compared to normal controls, a reduced volume of the entorhinal cortex and hippocampus has been observed in MCI patients (Convit et al., 1997; Du et al., 2001). The determination of hippocampal volume may thus contribute to the prediction of AD development in patients with MCI (Jack et al., 1999). Fluoro-2-deoxy-D-glucose positron emission tomography (FDG-PET) studies have revealed reduction of glucose metabolism in the MTL and posterior cingulate cortex of MCI patients, especially in ApoE- $\varepsilon 4$ carriers (Mosconi, 2005).

Due to the high rate of patients with MCI who develop AD, MCI is commonly considered as clinical pre-AD. Imaging techniques and cerebrospinal fluid (CSF) biomarkers (see below) may be helpful to identify incipient AD in MCI patients.

Subjective cognitive impairment (SCI) has recently been suggested as a preMCI stage in a possible SCI-MCI-AD disease continuum (Reisberg and Gauthier, 2008), making this population interesting for longitudinal studies as well. 


\subsubsection{The Neurobehavioral Cognitive Status Examination (Cognistat)}

The Neurobehavioral Cognitive Status Examination (Cognistat) (Kiernan et al., 1987; Schwamm et al., 1987) is a test of cognitive function. It usually takes less than 45 minutes to complete, depending on the cognitive status of the patient, which makes it suitable for use in the testing of large samples. However, it is important that trained staff performs the test. Cognistat includes subtests for orientation, attention, comprehension, repetition, naming, visuoconstruction, memory, calculation, similarities (verbal abstraction and concept formation), and judgment. The memory scale tests delayed verbal memory and includes cued recall. In the beginning of the test, the examiner asks general questions about the patients name, age, etc, before the examiner asks questions related to orientation (place and time). Next, the examiner tests memory and attention. Verbal memory is tested and the patient is asked to repeat a series of digits. The patient will be asked to recall the items he/she was asked to remember earlier. Spontaneous speech is tested by asking the patient to describe a detailed drawing. Language ability is further tested by observing the response to simple commands (comprehension) and by asking the patient to repeat phrases and sentences (repetition). In the last subtest of the language section, naming, the patient is asked to name parts of separate object when pointed to. Constructional ability is tested by having to draw an item, which was presented, on a stimulus sheet for ten seconds. Constructional ability is tested as the patient must fit plastic tiles into designs shown on a card. Calculation is tested by simple verbal mathematics. Reasoning consists of two subtests (similarities and judgment). Similarity is tested as the patient must explain in which way two concepts are similar. In the subtest for judgment the patient must show his/her ability to solve basic problem scenarios by answering questions demonstrating practical judgment.

\subsection{Alzheimer's disease}

\subsubsection{Background}

Accounting for approximately $60 \%$ of all dementia cases, Alzheimer's disease (AD) is the most common cause of dementia in the industrialized nations. In 2006, the worldwide prevalence was estimated at 26 millon, a number expected to quadruple in the next 40 years. This means that 1 in 85 persons will be affected by 2050 (Brookmeyer et al., 2007). In the western world, the AD prevalence in people older than 85 years of age is around $30 \%$. Besides cancer, stroke, and cardiovascular 
disease, $\mathrm{AD}$ has become one of the major causes of morbidity in the developed nations (Blennow et al., 2006; Tedeschi et al., 2008). This renders AD into a major public health problem. If early diagnosis and treatment could help delay disease onset and progression by as little as one year, the global AD burden would be significantly reduced (Brookmeyer et al., 2007).

$\mathrm{AD}$ is neuropathologically characterized by loss of synapses, neuron degeneration, extracellular senile plaques, and intracellular neurofibrillary tangles. The amyloid cascade hypothesis is an important hypothesis for the cause of AD. Imbalance in $A \beta$ production and clearance lead to $A \beta$ aggregation and formation of plaques. Recent research has highlighted the neurotoxicity of diffusible A $\beta$ oligomers (Blennow et al., 2006; Walsh and Selkoe, 2004). The formation of neurofibrillary tangles, another major component of $\mathrm{AD}$ pathogenesis, is believed to cause axonal dysfunction thereby compromising neuronal and synaptic function (Iqbal et al., 2005). Neurofibrillary tangles consist of abnormally hyperphosphorylated tau protein (Grundke-Iqbal et al., 1984). Tau is a microtubule-associated protein mainly located in neuronal axons. It is important for the stabilization of microtubuli and axonal maintenance (Drubin et al., 1988). However, it is yet not clear whether tau pathology and tangle formation are a cause or a consequence of the AD disease process.

According to the amyloid hypothesis of $\mathrm{AD}, \beta$-amyloid or precursors cause both nerve cell loss and memory failure. Genes causing familial early onset AD show non-allelic heterogeneity and are all related to metabolism of amyloid. The only established genetic risk factors for late onset $\mathrm{AD}$, Apolipoprotein $\mathrm{E}$, may be related to both amyloid metabolism and to the development of cerebrovascular pathology (see later in text).

There are three high penetrance genes which have been related to early onset familial AD. $\beta$-amyloid precursor protein (APP), is located on chromosome 21 and is triplicated in Down syndrome, possibly accounting for the early development of Alzheimer's disease in trisomy 21 individuals. Families with autosomal dominant early onset Alzheimer's disease harbor point mutations in APP, leading to amino acid changes at proteolytic sites for $\alpha, \beta$, and $\gamma$-secretases that normally are involved in processing the APP protein. Two other genes related to early onset familial AD are presenilin 1 and 2, located on chromosomes 14 and 1 respectively. Mutations in these genes are the most common causes of familial $\mathrm{AD}$ and they have been shown to 
increase production or alter the ratio of amyloid peptides (A $\beta 1-40$ and $A \beta 1-42)$ (Selkoe, 2002).

Histopathological confirmation still is the gold standard for a definite AD diagnosis. The National Institute of Neurological and Communicative Disorders and Stroke and the Alzheimer's disease and Related Disorders Association (NINCDSADRDA) have defined criteria for probable AD. The diagnosis of probable AD is based on clinical and neuropsychological examination, the presence of cognitive impairment confirmed by neuropsychological testing along with exclusion of other causes of dementia. The use of CT and MRI scans in the context of these criteria is essential to identify alternative causes of cognitive impairment (brain tumors, normal pressure hydrocephalus, subdural haematomas, etc) as well as concomitant cerebrovascular disease (Blennow et al., 2006).

New scientific knowledge about early AD, proteomic findings, and the availability of functional and structural imaging has led to a revision of the NINCDS-ADRDA criteria for research purposes (Dubois et el., 2007). As new AD biomarkers have become available, the new criteria propose the use of MRI, positron emission tomography (PET), and CSF analysis not only for exclusion of alternative causes of dementia, but as specific supportive criteria in addition to episodic memory impairment.

\subsubsection{Alzheimer's disease and white matter changes}

Small vessel disease and $\mathrm{AD}$ often coexist and patients with cerebrovascular disease have increased risk for AD (de la Torre, 2002; Snowdon et al., 1997). Clinical distinction between the two entities may be difficult, as both $\mathrm{AD}$ and microvascular disease lack focal signs initially and progress insidiously. In addition, ischemic brain disease and WML may also be etiologically linked to AD (Snowdon et al., 1997; Vermeer et al., 2003).

Established risk factors for vascular disease like hypercholesterolemia, hypertension, and hyperhomocysteinemia may increase the risk for sporadic AD (Gorelick, 2004; Napoli and Palinski, 2005; Casserly and Topol, 2004), and a reduced risk for AD after treatment of hypertension and hypercholesterolemia has been described (Casserly and Topol, 2004; Forette et al., 2002; Fassbender et al., 2001; Lim et al., 2005). 
Figure 1 shows the prevalence of WML and AD according to age group. WML occurs earlier than $\mathrm{AD}$, supporting the hypothesis that cerebrovascular events increase the risk of AD.

Figure 1: WML and AD prevalence adapted from Masani et al., 2003 and $\mathrm{Hy}$ et al., 2000.

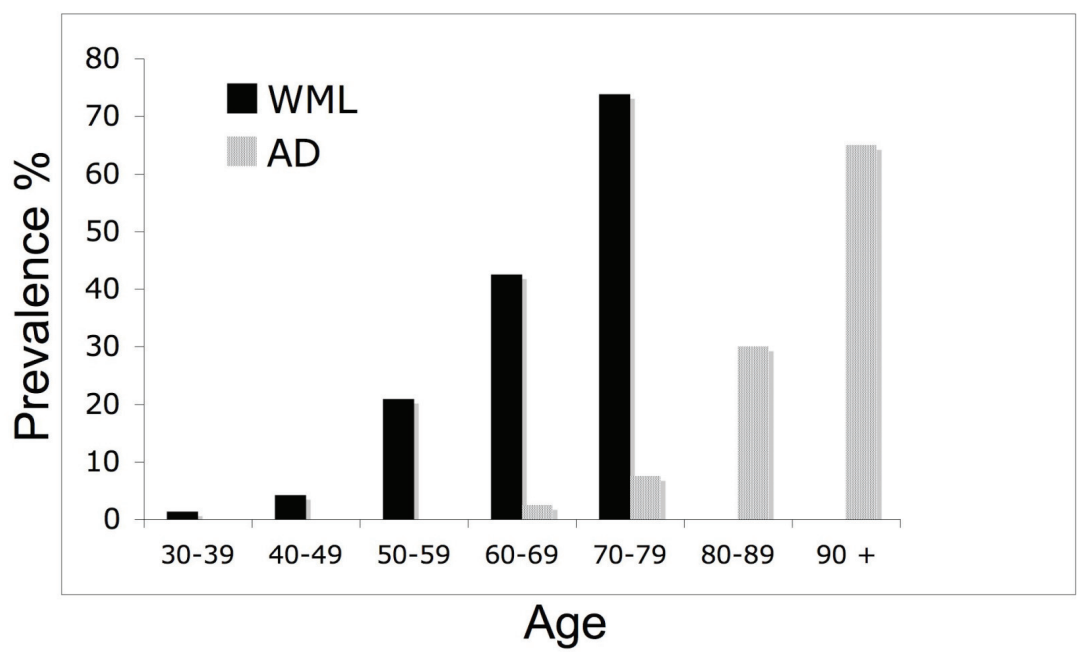

WML prevalence precedes $A D$ prevalence by 20 to 30 years.

WML have been associated with hippocampal atrophy in AD (de Leeuw et al., 2004), and a recent study of patients with cerebral autosomal dominant arteriopathy with subcortical infarcts and leucoencephalopathy (CADASIL) suggests that subcortical vascular lesions are associated with low CSF A $\beta 42$ (Formichi et al., 2008).

Experimental studies have suggested mechanisms that could account for this effect. Ischemic changes in the surroundings of neuronal tracts may lead to glial activation, formation of amyloid precursor protein (APP), and release of diffusible agents that may induce apoptosis (Sachdev et al., 2004; Wallin et al., 2000; Melton et al., 2003; Badan et al., 2003; Jin et al., 2001; Nihashi et al., 2001). After experimental white matter damage, studies suggest that amyloid could be deposited in the disconnected 
cortical regions, or APP could be transported to cortical regions from the site of damage along neuronal tracts (Yam et al., 1998; Murakami et al., 1998).

It has also been proposed that Wallerian degeneration may contribute to white matter changes (Englund, 1998; Leys et al., 1991). Supporting this notion, altered white matter myelination and a relationship between white matter gliosis and parenchymal A $\beta$ load have been described in AD patients (Chalmers et al., 2005; Roher et al., 2002). WML in patients with AD may therefore partly arise secondary to cortical pathology. However, white matter degeneration has also been found in patients with early AD without signs of cortical thinning (de la Monte, 1989), suggesting that white matter is affected before cortical degeneration occurs. Diffusion alterations in parahippocampal white matter of $\mathrm{AD}$ patients have been observed as well, and after correcting for hippocampal volume (Salat et al., 2008). These findings suggest that white matter alterations may represent an additional mechanism, besides cortical degeneration, in the AD disease process.

\subsection{White matter changes and cognition}

WML may affect subcortical-cortical networks, as well as cortical association and projection fibers, leading to cortical disconnection and causing cognitive affection (Catani and Ffytche, 2005; Nordahl et al., 2006; O'Sullivan et al. 2004).

WML are associated with cognitive loss and dementia (Artero et al., 2004; Prins et al., 2002, Prins et al., 2004), but the associations reported between ischemic WML and cognition are variable (Au et al., 2006; Breteler et al., 1994; Burns et al., 2005; de Groot et al., 2000a; Hunt et al., 1989; Longstreth et al., 1996; Reed et al., 2007; Sabri et al., 1999). Executive functions and information processing speed are most consistently found to be affected, whereas affection of memory is a less consistent finding (Catani et al., 2005; Jokinen et al., 2006; Prins et al., 2005; Salamon et al., 1966; Soderlund et al., 2006). The variability of the findings may be due to differences in methodology and different patient groups with various types of co-existing brain disease.

Both PV and SC WML have been associated with impaired cognition (de Groot et al., 2000a; Baum et al., 1996; Burns et al., 2005; Delano-Wood et al., 2008; Gold et al., 2007; Soderlund et al., 2006). However, the findings are inconsistent and it is not clear to what degree the effects of PV and SC WML on cognitive function differ. Due to separate anatomical locations, PV and SC WML affect different fiber 
tracts. PV lesions most likely affect projection and longer distance association fibers, whereas SC lesions affect short distance association fibers and cortical-subcortical networks (Brodal, 1998). These differences may lead to different modalities of impairment of cognitive function.

As most cognitive capabilities are sensitive to the effects of $\mathrm{AD}$, particularly delayed recall, the effects of WML alone are difficult to detect. Therefore, a subpopulation of patients without manifest or incipient $\mathrm{AD}$ is required to study the specific cognitive effects of WML. The use of CSF biomarkers is one possible way to stratify patients with cognitive impairment into groups more or less likely to suffer from incipient $\mathrm{AD}$.

As a part of the Papez-circuit (Papez, 1937), the posterior cingulum fibers play an important role in memory function as they connect the posterior cingulate gyrus with the medial temporal lobe (Buckner et al., 2005; Catani et al., 2002; Crosby, 1962). A number of recent studies have focused on cingulum fibers using diffusion tensor imaging (DTI). These studies have shown that white matter diffusion parameters correlate with working memory in healthy middle-aged and elderly adults (see below).

\subsection{Cerebrospinal fluid biomarkers}

The use of CSF biomarkers may contribute to early detection of AD (de Leon et al., 2007). Such markers have been suggested as adjunct markers for the diagnosis of "probable AD" in patients with episodic memory deficits (Dubois et al., 2007).

CSF biomarkers (tau and beta-amyloid proteins) for AD have a diagnostic specificity and sensitivity of around 85\% (Blennow and Hampel, 2003; Wiltfang et al., 2005). These markers have been shown to predict the development of clinical dementia and AD in patients with MCI (Diniz et al., 2007; Hampel et al., 2004; Hansson et al., 2006). In addition, these CSF biomarkers have been shown to distinguish $\mathrm{AD}$ in patients with vascular dementia, irrespective of co-existing subcortical cerebrovascular disease (Stefani et al., 2005). CSF biomarkers possess high sensitivity to differentiate early AD from normal aging, depression, Parkinson's disease, and alcohol dementia, but lower specificity with respect to other types of dementias, such as fronto-temporal and Lewy body dementia (Andreasen and Blennow, 2005). 
Low levels of CSF A $\beta 42$ have consistently been observed in patients with AD (Andreasen et al, 1999; Blennow and Hampel, 2003). An inverse correlation between CSF A $\beta 42$ levels and brain amyloid deposition has been established in pathological studies (Strozyk et al., 2003), including in-vivo amyloid imaging studies (Fagan et al., 2006; Forsberg et al., 2007). Experimental evidence further suggests that the reduction of $\mathrm{A} \beta 42$ seen in $\mathrm{AD}$ may be partly due to $\mathrm{A} \beta 42$ deposition in amyloid plaques (Kawarabayashi et al, 2001). However, one should not loose sight of the fact that $A \beta 42$ serves as a surrogate marker, and reduced levels may also be seen in other neurodegenerative diseases (Sjogren et al., 2002; Otto et al., 2000; Noguchi et al., 2005; Mollenhauer et al., 2005).

Elevated CSF levels of total Tau protein (T-tau) and phospho-Tau (P-tau) have been observed in different neurodegenerative diseases and are probable markers for axonal damage and tangle formation (Blennow and Hampel, 2003; Sunderland et al., 2003; Sussmuth et al., 2001; Teunissen et al., 2005). High levels of CSF T-tau may indicate the extent of neuronal damage. In the rapid progressive neurodegenerative disorder Creutzfeldt-Jakob disease (CJD), very high levels of CSF T-tau have been observed (Otto et al., 1997; Skinningsrud et al., 2008). Likewise, in acute ischemic stroke a positive correlation between increased CSF T-tau and the size of the infarction have been reported (Hesse et al., 2000). The P-tau isoform does not seem to be elevated in acute ischemic stroke or CJD. Since this particular isoform represents the phosphorylation state of tau protein in the brain it may be a better marker for AD (Blennow and Hampel, 2003).

In combination with careful clinical examination, medical history, and brain imaging, CSF biomarkers may in fact increase the diagnostic accuracy in early AD.

\subsection{Apolipoprotein E}

Apolipoprotein E- $\varepsilon 4$ (ApoE- $\varepsilon 4)$ carrier status is the only well established genetic risk factor for late onset AD (Corder et al., 1993). APOE is a protein with many different functions related to lipid metabolism and lipid transport between cells (Herz and Beffert, 2000). The gene is located on chromosome 19, and three common isoforms

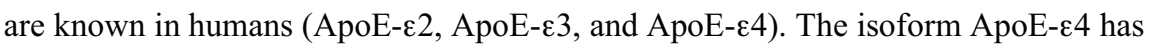
been related to increased risk of developing AD (Farrer et al., 1997). For patients who 
carry two ApoE- $\varepsilon 4$ alleles, the chance of developing AD by the age of 85 is in the order of $50 \%$ to $90 \%$ (Corder et al., 1993).

It is yet not clear through which mechanisms ApoE- $\varepsilon 4$ increases the risk for AD. However, considerable evidence indicates that ApoE- $\varepsilon 4$ may interact with APP processing and induce aggregation and binding, as well as cause reduced clearance of $\beta$-amyloid (Wisniewski et al., 1993; Strittmatter et al., 1993; Holtzmann et al., 2000; Bales et al., 1997). ApoE-ع4 has also been related to cardiovascular and cerebrovascular disease (Eichner et al., 2002; McCarron et al., 1999). In particular small vessel disease (arteriolosclerosis) and micro infarcts have been associated with ApoE- $\varepsilon 4$ in brains of AD patients (Yip et al., 2005), and ApoE- $\varepsilon 4$ positive AD patients have higher WML load than ApoE- 44 non-carriers (Bronge et al., 1999). The latter suggests that ApoE- $\varepsilon 4$ may play a role in the cerebrovascular pathology frequently observed in $\mathrm{AD}$ patients. However, the role of the different ApoE genotypes in the development of cerebrovascular disease and WML needs to be further clarified (for review see Turner and Fornage, 2002).

\subsection{Diffusion Tensor Imaging}

\subsubsection{General background}

Diffusion tensor imaging (DTI) can be used to quantify white matter integrity (Le Bihan et al., 2001). DTI may reveal white matter changes and degradation of white matter fiber bundles not detectable with conventional MRI (Deo et al., 2006; Taylor et al., 2007). DTI techniques are mostly based on diffusion of water molecules. Diffusion of molecules is restricted by cell membranes and fiber structures. In cerebral white matter, axonal membranes and myelin represent such barriers and diffusion parallel to fiber bundles is greater than perpendicular diffusion. The principle of restricted molecular mobility in some directions is called "diffusion anisotropy". Fractional anisotropy (FA) can be calculated from the diffusion tensor eigenvalues and is a measure of directional diffusivity (Basser et al., 1994; Le Bihan et al., 2001). FA varies between 0 (isotropic diffusion / equal diffusion in all directions) and 1 (entirely anisotropic / undirectional diffusion). The FA parameter is expected to be reduced when axonal damage or dysmyelination occur. Mean diffusivity (MD) is a measure of diffusion averaged in all directions and indicates the magnitude of diffusion. MD will typically increase when axonal membranes or 
myelin are damaged (Le Bihan et al., 2001; O’Sullivan et al., 2001; Ulug et al., 1999).

The diffusion eigenvalues may be separated into components, which describe diffusivity parallel $(\lambda 1)$ or perpendicular $(\lambda 2$ and $\lambda 3)$ to the axonal tracts (Basser et al., 1994; Xue et al., 1999). Axial diffusivity (DA, parallel to axon tracts) and radial diffusivity (DR, perpendicular to axon tracts) may be helpful to better describe the underlying pathology of white matter alterations reflected by FA (Wang et al., 2008). After experimental ischemia, reduced DA is followed by increased DR mirroring the sequence of Wallerian degradation of axons and myelin components in the CNS (George and Griffin 1994a; George and Griffin 1994b; Sun et al., 2008). It has been suggested that decreased DA may reflect axonal loss and that increased DR may be associated with dysmyelination (Pierpaoli et al., 2001; Song et al., 2003; Song et al., 2002). Parts of the DA and FA changes observed in the acute phase after axonal damage may be transient, and DR changes observed in the chronic stage after axonal damage may represent myelin degradation (Concha et al., 2006). Experimental evidence from contusion injuries also suggests that changes in DR are sensitive to secondary changes beyond the site of the primary histologically defined lesion (Budde et al., 2007).

Studies have reported an association between age-related cognitive decline and reduced FA (Charlton et al., 2006). In addition, reduced (FA) in posterior cingulum fibers has been observed in MCI patients compared to normal controls (Fellgiebel et al., 2005; Zhang et al., 2007). Few studies have examined directional diffusivity (DR and DA) in MCI and AD patients, and so far the findings have been inconclusive. One study reported reduced DA, consistent with axonal degeneration, in the temporal lobe of AD and MCI patients (Huang et al., 2007), whereas another study focused on frontal regions and found signs of altered myelination (increased DR) in frontal white matter of early AD patients (Choi et al., 2005).

\subsubsection{Regions of interest (ROI) analysis}

The manual placement of regions of interest (ROI) in known white matter fiber tracks is a common method to measure diffusion parameters. First, MD, FA, individual eigenvalue images, and color-coded eigenvector (cDTI) maps are generated. In the cDTI maps the pixel color and intensity reflect the principal diffusion direction and FA magnitude, respectively. The nordicICE Basis and Diffusion Modules (NordicImagingLab AS, Bergen, Norway) is a preferred software that may be used 
for this purpose, but other programs for DTI processing are available (Zhang et al., 2007).

When placing the ROI it is important to ensure that partial CSF or grey matter volume is avoided. This can be done by co-alignment of the DTI data ( $b=0$ scans) with the MP-RAGE images (e.g. by using Statistical Parametric Mapping (SPM5), Wellcome Trust Centre for Neuroimaging, London, UK). White matter segmentations may then be created from the co-registered MP-RAGE sequence using the segmentation module provided by SPM5. The white matter masks as well as the cDTI maps may be used for orientation to avoid possible artifacts due to partial CSF or grey matter volume. ROI are usually placed in the part of the fiber tract with the highest signal intensity. To ensure the proper anatomical placement of the ROI between subjects, it is helpful to use the cDTI map in addition to comparing images.

\section{Figure 2: Illustration of region of interest (ROI) placements}

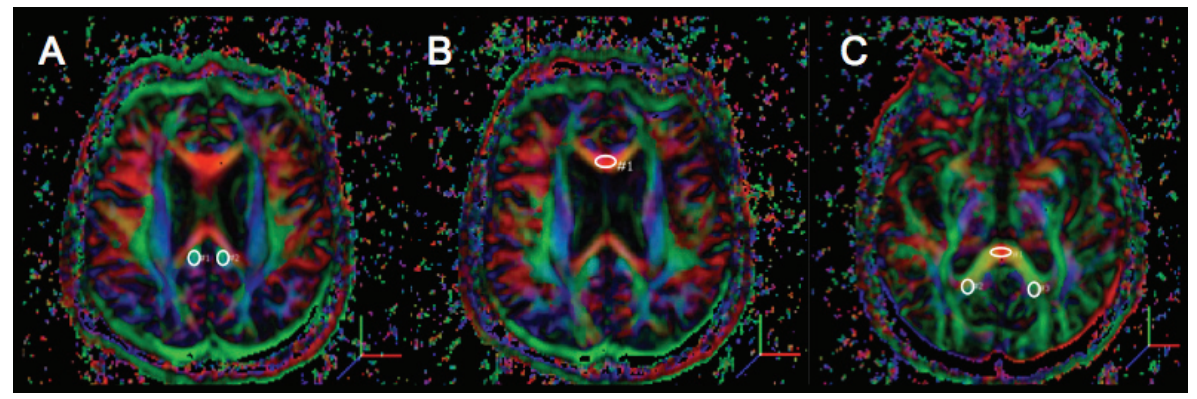

The figure illustrates the placement of regions of interest (ROI) in the color-coded (cDTI) map. ROI are shown in Cingulum fibers (A), genu corpus callosum (B), splenium corpus callosum and forceps major $(C)$. 


\section{AIMS OF THE PRESENT STUDY}

The main goal of the present work was to examine the relationships between white matter changes, risk factors for cerebrovascular disease and CSF biomarkers for Alzheimer disease (AD), but we also asked whether and how white matter changes relate to cognition in patients with cognitive impairment. Within the framework of this thesis, we posed and attempted to answer the following specific questions:

Is there a link between white matter lesions and amyloid pathology?

The relationship between cerebrovascular disease and cerebral degenerative disease has been widely studied, with experimental data showing that there might be a link between ischemia and amyloid deposition. We therefore aimed to test this hypothesis in patients with cognitive impairment by investigating a possible relationship between white matter lesion (WML) load (as a measure of cerebrovascular disease) and the CSF biomarker A $\beta 42$ (a surrogate marker for amyloid deposition in the brain) (Paper I).

Do ApoE genotype and white matter lesions interact in the development of amyloid pathology?

Both cerebrovascular disease and ApoE- $\varepsilon 4$ are known risk factors for AD. Paper I showed that both WML and the ApoE- $\varepsilon 4$ genotype might increase the risk of having low CSF A $\beta 42$. These findings led to the hypothesis that these two important risk factors for $\mathrm{AD}$ might interact (paper IV) in the development of amyloid pathology as measured by CSF A $\beta 42$. Paper IV aimed to test this hypothesis by analyzing the risk of having low CSF A $\beta 42$ in ApoE- $\varepsilon 4$ carriers versus non-carriers in patient cohorts with either low or high WML loads.

Are white matter lesions related to cognitive loss, and does the location of white matter lesions matter?

WML appear in all areas of the cerebral white matter and consistently affect fiber tracks connecting areas of the brain, which are important for cognitive function. WML has therefore been related to axonal damage and gliosis in imaging and histopathological studies. If WML lead to damage of fiber tracks it is conceivable that 
WML will affect cognitive function. As most cognitive capabilities are sensitive to the effects of $\mathrm{AD}$, particularly delayed recall, a sub-population of patients without manifest or incipient $\mathrm{AD}$ is needed to study the specific cognitive effects of WML. For this purpose, we decided to compare effects of WML on cognitive loss in patients with normal and pathological CSF A $\beta 42$ values (Paper II).

The relationship between subtypes of WML - periventricular (PV) and subcortical (SC) - is not yet clear. There is experimental evidence of closely related underlying pathomechanisms, but some studies argue that these WML subtypes represent entirely different disease processes. The location of these WML also suggests that they affect different fiber tracks, and therefore will affect cognition in different ways. For this reason, we aimed to investigate the co-existence of WML subtypes and their relation to cognitive impairment (paper III).

Are diffusion tensor parameters related to Tau pathology and could these changes be part of the development of mild cognitive impairment?

Reduced white matter integrity investigated with diffusion tensor imaging (DTI) has been observed in patients with mild cognitive impairment (MCI) compared to normal controls, particularly in areas related to the memory network. DTI parameters reflect reduced white matter integrity and axonal damage. Also, Tau pathology may reflect axonal dysfunction. As Tau protein in CSF has been shown to be elevated in patients at risk of developing $\mathrm{AD}$, we hypothesized that white matter diffusivity changes would be more apparent in patients with elevated CSF T-tau levels than in patients with normal T-tau levels (paper V). 


\section{ABSTRACTS / SUMMARY OF RESULTS}

\section{Paper I}

\section{Associations between white matter lesions, cerebrovascular risk factors, and low CSF Aß42}

Objective: To analyze a putative relationship between white matter lesions (WML), risk factors for WML, and Alzheimer disease (AD) as measured with the surrogate marker CSF A $\beta 42$.

Methods: We analyzed effects of acquired risk factors for cerebrovascular disease and WML on AD as measured with an intermediate marker, CSF A $\beta 42$. A total of 127 consecutive patients with subjective memory impairment (mean age 66 years; 57 women) investigated at a university-based memory clinic had brain MRI scans. WML were rated on a 12-point scale with a semi-quantitative procedure. We used path analysis with established and possible risk factors for WML and for reduced CSF A $\beta 42$ (age, hypertension, hyperhomocysteinemia, hypercholesterolemia, APOE- $\varepsilon 4$ ) as variables.

Results: The WML score was 1.5 points higher $(p<0.05)$ in hypertensive than in nonhypertensive patients, and 1.9 points higher $(p<0.05)$ in patients with hyperhomocysteinemia than in those with normal homocysteine levels. Hypercholesterolemia increased the probability of low CSF A $\beta 42$ levels by 0.2 $(p<0.05)$. For each point increase in WML score the probability of low CSF A $\beta 42$ levels increased by $0.03(p<0.05)$. APOE- $\varepsilon 4$ was associated with reduced CSF A $\beta 42$ $(p<0.01)$.

Conclusions: Hypercholesterolemia, APOE- $\varepsilon 4$, and white matter lesions may contribute to low CSF A $\beta 42$ by independent mechanisms.

If WML load increases the risk of low CSF A $\beta 42$ levels and reduced levels of CSF A $\beta 42$ levels are associated with amyloid deposition, this indirectly implies a relationship between ischemic changes in white matter and cortical pathology as seen in Alzheimer's disease. 


\section{Paper II}

\section{White matter lesion severity is associated with reduced cognitive performances in patients with normal CSF A $\beta 42$ levels}

Objective - To identify possible associations between white matter lesions (WML) and cognition in patients with memory complaints, stratified in groups with normal and low CSF A $\beta 42$ values.

Material and Methods - 215 consecutive patients with subjective memory complaints were retrospectively included. Patients were stratified in two groups with normal $(n=127)$ or low $(n=88)$ CSF A 342 levels (cut-off $450 \mathrm{ng} / \mathrm{L}$ ). Cognitive scores from the Mini Mental State Examination (MMSE) and the Neurobehavioral Cognitive Status Examination (Cognistat) were used as continuous dependent variables in linear regression. WML load was used as a continuous independent variable and was scored with a visual rating scale. The regression model was corrected for possible confounding factors.

Results - WML were significantly associated with MMSE and all Cognistat subscores except language (repetition and naming) and attention in patients with normal CSF A 342 levels. No significant associations were observed in patients with low CSF A $\beta 42$.

Conclusions - WML were associated with affection of multiple cognitive domains, including delayed recall and executive functions, in patients with normal CSF A $\beta 42$ levels. The lack of such associations for patients with low CSF A $\beta 42$ (i.e. with evidence for amyloid deposition), suggests that amyloid pathology may obscure cognitive effects of WML. 


\section{Paper III}

\section{White matter lesion subtypes and cognitive deficits in patients with memory impairment}

Aim: To analyze the relationship between periventricular (PV) and subcortical (SC) white matter lesions (WML) and cognitive function in patients with memory impairment.

Methods: 253 patients with Global Deterioration Scale score $\geq 3$ referred to a university based memory unit due to memory complaints were included (mean age 69.7 years, 124 females). Cognitive function was assessed with Mini Mental State Examination (MMSE) and Neurobehavioral Cognitive Status Examination (Cognistat) and full test results were available for 217 patients. PV and SC WML loads (semi-quantitative rating on axial T2-MRI scans) were used in linear regression as predictors of cognition.

Results: MMSE was significantly correlated with SC WML ( $\mathrm{p}=0.005)$, but not with PV WML ( $\mathrm{p}=0.19)$. Cognistat tests for orientation, comprehension, visuoconstruction, calculation, similarities, and judgment were negatively correlated with SC WML $(\mathrm{p}<0.01)$, and verbal memory with parieto-occipital SC WML $(\mathrm{p}<0.05)$. Visuoconstruction and calculation were negatively correlated with PV WML $(p<0.05)$. Parieto-occipital WML were more strongly related to cognition than frontotemporal WML. Only SC WML were significantly correlated with cognition when PV and SC WML were entered simultaneously in the regression model.

Conclusions: The results suggest that mainly SC WML are related to cognitive loss, and that WML in parieto-occipital regions have stronger negative effects on cognition than WML in fronto-temporal regions. The findings further suggest a possible sequential development of WML (PV WML $\rightarrow$ SC WML). 


\section{Paper IV}

\section{White matter lesion load increases the risk of low CSF A $\beta 42$ in apolipoprotein $E$ $\varepsilon 4$ carriers.}

Background: White matter lesions (WML) are age-related manifestations of ischemic cerebrovascular disease, which increase the risk for Alzheimer's disease (AD). The apolipoprotein E $\varepsilon 4$ (ApoE- $\varepsilon 4)$ genotype is an established risk factor for late onset $\mathrm{AD}$ and has been related to low levels of $\mathrm{A} \beta 42$ in the cerebrospinal fluid (CSF) and to cerebrovascular disease. The aim of the present study was to analyze the relationship between WML, ApoE- $\varepsilon 4$ genotype, and low CSF A $\beta 42$ in patients recruited from a memory unit.

Methods: 235 patients from 40 to 91 years of age (mean 69 years; 119 women) with different degrees of cognitive impairment were included from a university based memory clinic. Brain MRIs were performed and periventricular (PV) and subcortical (SC) WML were rated on axial T2 MRI images. ApoE genotype and CSF A $\beta 42$ levels were analyzed. Patients were stratified in three groups according to WML load. Group $1(\mathrm{n}=70)$ had no WML or only small amounts of PV or SC WML, WML group $2(n=83)$ had high amounts of PV WML and low amounts of SC WML, and WML group 3 ( $\mathrm{n}=82$ ) had high amounts of both PV and SC WML. In the three WML groups, ApoE- $\varepsilon 4$ genotype was used in logistic regression as predictor for low CSF A $\beta 42$ (cut-off value $\leq 450 \mathrm{ng} / \mathrm{L}$ ). Age and hypercholesterolemia were entered as covariates in the regression model.

Results: The odds ratio (OR) of having low CSF A $\beta 42$ was significantly increased in the presence of ApoE- $\varepsilon 4$ only in WML group 3. WML group 1 (OR [95\%CI] 1.39 $[0.49,3.98], \mathrm{p}=0.53)$; WML group 2 (OR [95\%CI] $2.38[0.86,6.56], \mathrm{p}=0.093)$; WML group $3(\mathrm{OR}[95 \% \mathrm{CI}] 3.69$ [1.38, 9.88], $\mathrm{p}=0.009)$.

Conclusion: A high WML load may interact with the ApoE- $\varepsilon 4$ genotype and increase the risk for reduced CSF A $\beta 42$ in patients with cognitive impairment. 


\section{Paper V}

\section{Cingulum fiber diffusivity and CSF T-tau in patients with subjective and mild cognitive impairment}

Background: Diffusion Tensor Imaging (DTI) and CSF biomarkers are useful diagnostic tools to differentiate patients with mild cognitive impairment (MCI) from normal controls, and may help predict conversion to dementia. Total Tau protein (Ttau) and DTI parameters are both markers for axonal damage, thus it is of interest to determine whether DTI parameters are associated with elevated CSF T-tau levels in patients with cognitive impairment.

Methods: Patients with subjective cognitive impairment (SCI) and MCI were recruited from a university based memory clinic. Regions of interest were used to determine fractional anisotropy (FA), radial (DR) and axial (DA) diffusivity in known white matter tracts in patients with MCI $(n=39)$ and SCI $(n=8)$ and 26 cognitively healthy controls.

Results: Significant lower FA and higher DR values were observed in patients with pathological vs. patients with normal CSF T-tau levels and vs. controls in left posterior cingulum fibers. T-tau values were negatively correlated with FA and positively correlated with DR values in the posterior cingulum fibers. Conclusion: Cingulum fiber diffusivity was related to T-tau pathology in SCI/MCI patients and altered DR may suggest that loss of myelin contributes to early white matter changes in patients at risk of developing Alzheimer's disease. 


\section{GENERAL DISCUSSION}

Is there a link between white matter lesions and amyloid pathology?

Previous studies point to a link between ischemic damage in white matter and cortical Alzheimer pathology, but no causal relationship has been definitely established.

Overlapping risk factors between cerebrovascular disease (CVD) and Alzheimer's disease (AD) suggest a link between the two disease processes. It has been argued that non-genetic late-onset $\mathrm{AD}$ is triggered by $\mathrm{CVD}$, and therefore should be regarded as a primary vascular disease (de la Torre, 2002). This hypothesis is supported by neuropathological and experimental studies which show that hypoxia influences amyloid percursor protein (APP) metabolism and increases deposition of amyloid- $\beta$ (A $\beta$ ) (Jendroska et al., 1995; Sadowski et al., 2004). In addition, hypoxia has been shown to increase the $\beta$-secretase cleavage of APP leading to an increased production of $A \beta 42$ protein in mice (Sun et al., 2006).

A number of studies have shown that the amount of amyloid plaques increases with age, and autopsies of elderly without cognitive impairment have revealed pathohistological findings similar to those seen in AD (Green et al., 2000; Knopman et al., 2003). Age, which is also strongly related to WML, therefore represents an important confounding factor when investigating the relationship between WML and amyloid pathology. A recent study even suggests a relationship between age and CSF A $\beta 42$ in cognitively healthy individuals (Bouwman et al., 2008). However, cerebrovascular changes, like WML, were not corrected for in these studies. The main finding of paper I was that WML increased the risk of having pathological levels of CSF A $\beta 42$. This relationship was observed despite that there was no significant difference in age between patients with normal and pathological CSF A $\beta 42$ levels (see table 1 later in text). The findings in paper I therefore further support previous evidence for links between age, hypertension, hyperhomocysteinemia and WML, as well as between hypercholesterolemia and ApoE- $\varepsilon 4$ and low CSF A $\beta 42$. Hypercholesterolemia is not only a vascular risk factor but has previously also been directly implicated in amyloid formation as a result of altered metabolization of APP (Wolozin, 2004; Ehehalt et al., 2003; Rebeck, 2004). In accordance with previous studies, we did not find that hypercholesterolemia was related to WML in the age group studied in paper I (Breteler et al., 1994; Sawada et al., 2000). WML and hypercholesterolemia could therefore independently contribute to low CSF A 342 in subgroups of patients 
(Casserly and Topol, 2005). However, our findings support the association between WML and the two cerebrovascular risk factors, hyperhomocysteinemia and hypertension (Vermeer et al., 2002).

As shown in the introduction (figure 1), MRI scans of patients without known memory problems also indicate an enhanced accumulation of WML in the age group studied in paper I (Masana et al., 2003). WML therefore probably affect the majority of the elderly population, and non-ischemic cases are expected to be rare in older patients. As age-associated WML prevalence obviously occurs prior to that of increased AD prevalence (cf. Figure 1), the results of paper I suggest that WML could predispose susceptible patients for development of AD. Our findings clearly support the hypothesis that white matter lesions are linked to amyloid pathology as measured by CSF A $\beta 42$.

\section{Do ApoE genotype and white matter lesions interact in the development of amyloid pathology?}

As both ischemia and ApoE- $\varepsilon 4$ have been related to $ß$-amyloid metabolism, we hypothesized that there may be a connection and possible interaction between ischemic WML, ApoE- $\varepsilon 4$ and degenerative processes that involve APP metabolism. The negative correlation between age and CSF A $\beta 42$ may be induced by ApoE- $\varepsilon 4$ status (Peskind et al., 2006). However, due to the very strong connection between increasing WML and increasing age (Masana et al., 2003), if not considered, both age and WML may confound the analysis of ApoE- $44 / \mathrm{CSF}$ A $\beta 42$ relationships.

Experimentally, ischemia has been proven to elicit increased APP expression (Nihashi et al., 2001). Accordingly, increased amounts of APP have been described intraaxonally in cases with subcortical ischemia (Akiguchi et al., 1997). Evidence has been presented for effects of ApoE- $\varepsilon 4$ on processing of APP, as well as effects on binding, aggregation and deposition of amyloid (Strittmatter et al., 1993; Sanan et al., 1994; Selkoe, 2003). Interaction between ischemia and ApoE- $\varepsilon 4$ in the development of amyloid pathology may be studied in humans by comparing the effect of ApoE- $\varepsilon 4$ on CSF A $\beta 42$ in patients with different grades of WML severity, as shown on MRI scans. In paper I we described an association between the total amount of WML and low CSF A $\beta 42$. In a possible interaction between cerebrovascular disease and AD, severe subcortical WML may have a more pronounced effect than periventricular 
lesions that are more distant from the cortex. In addition, the ApoE- $\varepsilon 4$ genotype may influence the metabolism of APP (Strittmatter et al., 1993) facilitating a drop in CSF A 342 . In paper IV, patients with available analysis of CSF and ApoE genotype from paper III were stratified according to WML load. As described in paper III, high amounts of subcortical WML were only seen in patients with periventricular WML. In contrast, high amounts of periventricular WML were seen in patients without subcortical affection. The distribution of PV and SC WML may therefore suggest a sequential development of WML, providing the biological basis for partitioning cases in groups with less and more WML.

The results in paper IV suggest that there may be an interaction between WML and ApoE- $\varepsilon 4$ in the development of low CSF A $\beta 42$. The relationship between WML and $\mathrm{A} \beta 42$ was dependent on the presence of ApoE- $\varepsilon 4$ and the results demonstrate that the combination of ApoE- $\varepsilon 4$ and high WML load may increase the odds of having low CSF A $\beta 42$. After regressing out age and hypercholesterolemia in the group analysis, we found that the odds of having a low CSF A $\beta 42$ value was significantly increased in the presence of ApoE- $\varepsilon 4$ only in patients with high WML load (WML group 3). The findings in paper IV therefore support the hypothesis that the co-existence of high white matter lesion load and the ApoE- $\varepsilon 4$ allele increases the risk of having low CSF $\mathrm{A} \beta 42$.

Are white matter lesions related to cognitive loss, and does the location of white matter lesions matter?

Several studies have reported associations between WML and cognitive impairment (e.g. Gold et al., 2007; Au et al., 2006; Longstreth et al., 1996). The strongest associations between WML and cognition involve cognitive functions that are mainly dependent on temporal and frontal structures, including associative pathways (Jokinen et al., 2006).

Paper II describes WML-dependent cognitive loss in a population without evidence of amyloid deposition based on CSF-analysis. While the results showed a consistent correlation between increasing WML and cognitive loss, larger effect sizes (higher B-values) and higher levels of significance suggested a stronger relationship in the group with normal $A \beta 42$ levels than in the one with low values. This may be 
because the more subtle effects of WML may be obscured by the more predominant effects on cognition of cortical amyloid deposition in patients with low CSF A $\beta 42$. The results delineate a profile of cognitive loss resulting from WML alone. As the effect sizes were largest on categories of verbal memory, similarities, judgment and visuoconstruction, the results presented in paper II support earlier reports suggesting that WML are related to cognitive domains that are mainly dependent on temporal and frontal structures, as well as associative pathways.

The association between increased WML and reduced verbal memory (after exclusion of cases with CSF-evidence for amyloid deposition) suggests that reduced delayed memory is also part of the spectrum of vascular cognitive disorder.

The results of paper III further indicate that subcortical (SC) WML are more strongly related to cognitive function than periventricular (PV) WML. These findings are supported by some studies (Baum et al., 1996; Delano-Wood et al., 2008), whereas others have reported that PV WML are more strongly related to cognition (de Groot et al., 2000; Burns et al., 2005). Despite these inconsistencies, it may be reasonable to conclude that both PV and SC WML may have effects on cognition. It has been argued that since PV WML probably affect long distance association fibers, they are more prone to affect cognitive function (de Groot et al., 2000). PV and SC WML often co-exist and SC WML are likely to affect cortical-subcortical networks.

In paper III all patients with high SC WML loads also had high loads of PV WML. This suggests that SC WML may represent a more advanced white matter affection than PV WML, thereby explaining why we found that they were more strongly related to cognitive impairment. We further examined whether WML in fronto-temporal (F-T) and parieto-occipital (P-O) regions affect cognition differently. We found that WML in P-O regions were more strongly related to cognitive impairment than WML of the F-T regions. In paper II we observed a relationship between total WML (Wahlund scale) and verbal memory in the entire patient group. In paper III we did not observe a significant relationship between whole brain PV and SC WML scores and verbal memory. The discrepancy with regard to WML and memory may be due to the different scales used in the two papers, and also to the effect of AD pathology on cognition (see below). However, P-O SC WML were significantly related to reduced verbal memory. White matter in the parieto-occipital regions contains fiber networks that are important for memory function. Disruption of cortical regions in these areas (e.g. posterior cingulate and lateral parietal cortex) may 
thus contribute to impaired memory (Buckner et al., 2005). This could be a plausible explanation for our findings that only WML of the P-O regions were negatively correlated with memory. Previous studies, which have reported a lack of relationship between WML and memory, have not analyzed possible differences between F-T and P-O WML (Baum et al., 1996; Delano-Wood et al., 2008). Even though P-O WML showed an overall stronger relationship with cognition, the results in paper III also indicated that SC WML of the F-T regions were strongly and negatively correlated with several cognitive domains including visuoconstruction, similarities and judgment. This is in line with other studies, which have related WML to deficient frontal-subcortical network functions (executive functions and processing speed) (Delano-Wood et al., 2008; Inzitari et al., 2000).

Paper III also focused on describing the subtypes of WML and their relationship to cognitive function. The question whether PV and SC WML represent different disease mechanisms or whether they represent a continuum of cerebrovascular disease, remains unresolved. However, it has been observed that WML often extend from periventricular areas into subcortical white matter with increasing WML volume and severity (DeCarli et al., 2005). We found that PV WML were present in a younger age group than SC WML. This could be explained by the theory presented by DeCarli and colleagues suggesting that PV WML occur before more advanced SC WML.

The etiopathology of PV and SC WML are similar and ischemic events play an important part (Ward and Brown, 2002). PV and SC regions are perfused by pial end arterioles (De Reuck, 1971), with PV regions lying in the distal part of the perfused region. Arteriolosclerosis starting distally in deep penetrating end arterioles could explain that PV WML may occur before SC WML. As previously shown, we also found that PV and SC WML were strongly correlated. The strong correlation between the PV and SC WML subtypes described here suggests etiopathological similarities, but as mentioned, differences in tissue response and vascular risk factors between WML in the two regions have been described (Simpson et al., 2007; Lazarus et al., 2005). The hypothetical sequential nature of PV and SC lesions and putative etiopathological differences between the lesion subtypes need to be clarified in prospective studies. If PV lesions herald white matter disease, this early stage may be important for the initiation of therapy for patients at risk for more severe affection. 
Collectively, the findings of this thesis support the hypothesis that WML are related to reduced cognitive function. The findings further suggest that the localization of WML matters, but this may be because SC WML represent a more advanced stadium than WML in PV regions.

Are diffusion tensor imaging parameters related to Tau pathology and may these changes be part of the development of cognitive impairment?

Over the last two decades Diffusion Tensor Imaging (DTI) has emerged as an important non-invasive technique to investigate disease processes related to white matter changes and axonal damage. As discussed earlier, there seems to be a link between cerebrovascular disease and $\mathrm{AD}$, and both cerebrovascular changes and $\mathrm{AD}$ pathology probably occur years before the manifestation of cognitive impairment and dementia. To detect early events in the development of cognitive impairment, the combination of advanced neuroimaging like DTI and the use of biomarkers (e.g. from CSF) must be applied before full-blown dementia occurs. Patients with subjective and mild cognitive impairment (SCI and MCI) are at risk of developing dementia (Reisberger and Gauthier, 2008). These patients therefore are of high interest when studying disease development. Several DTI studies have revealed reduced white matter integrity in MCI and $\mathrm{AD}$ patients. In addition, decreased connectivity from areas related to the memory network (hippocampus and posterior cingulate cortex) to the rest of the brain has been described (Fellgiebel et al., 2005; Zhang et al., 2007; Zhou et al., 2008).

As both DTI and CSF T-tau alterations have been related to axonal damage, paper $\mathrm{V}$ aimed to examine the relationship between these two parameters in patients at risk of developing AD. The patient population included both SCI and MCI, and Ttau was used to stratify the group. In Paper V we found that elevated CSF T-tau values were related to lower FA and increased DR in SCI/MCI patients. Signs of decreased FA and increased DR in posterior cingulum fiber tracts of these patients indicate early tau-related white matter alterations. Increased DR may reflect loss of myelin (Pierpaoli et al., 2001; Song et al., 2003; Song et al., 2002), but DR is a sensitive measure, possibly also reflecting distant pathological processes (Budde et al., 2007). Our findings in the left posterior cingulum bundle are in line with previous studies of MCI patients (Fellgiebel et al., 2005; Zhang et al., 2007). The significant FA and DR alterations we observed in the genu of corpus callosum may indicate that 
early white matter pathology also appear in neocortical connections in patients at risk of developing AD. Paper V did not reveal group differences in DA, but axon loss with transient effects on DA can not be excluded (Concha et al., 2006; Sun et al., 2008). Moreover, the observed association between DR and CSF T-tau levels may reflect underlying axonal affection (Teunissen et al., 2005).

In addition to axonal damage, Tau pathology has also been related to hippocampal atrophy (Adalbert et al., 2007; de Leon et al., 2007). In a subsample of the cohort studied in paper V, we have reported associations between pathological CSF biomarkers and reduced hippocampal volume and cortical thinning (Fjell et al., 2008). We found no association between hippocampal volume and directional diffusivity in the sample studied in paper V, but we did observe that both FA/DR in white matter tracts and hippocampal volume were associated with CSF T-tau levels. This fully agrees with the findings of Salat et al. (2008) suggesting that white matter alterations (demyelination or reduced axonal integrity) may represent an additional mechanism, besides cortical degeneration, in the AD process.

The results of paper V support the hypothesis that Tau pathology in the CSF may be related to axonal damage as measured with DTI. Since Tau pathology in patients with cognitive impairment is related to $\mathrm{AD}$, the observed DTI changes may represent early events in the disease process. Paper V further substantiates the importance of using CSF analysis and neuroimaging to differentiate patients with cognitive impairment at an early stage. However, follow up studies are needed to detect potential differences in disease development between these subgroups of SCI/MCI patients.

\section{Methodical aspects and limitations}

The patients in this thesis were all admitted to a university based memory clinic due to cognitive impairment of different degrees. As all patients sought help because of cognitive problems, one may expect these patients to have more pathologic findings (e.g. WML) than would be observed in the average population without overt cognitive problems. Due to possible paradoxical relationships between cerebrovascular risk factors (e.g. blood pressure levels) and WML when studied in high age groups (Turner and Fornage, 2002), paper I included patients between 40-75 years of age. In paper II-IV, inclusion was less restrictive than in paper I and no age limit was used in 
the inclusion criteria. The patient cohort studied in the subsequent papers II-IV was therefore larger than in paper I. The age range extended from 40 to 91 years.

Path analysis, which is a form of multiple regression analysis (Bollen, 1989) was used to test the hypothesis in paper I. The path analysis model implies a set of covariances among all pairs of variables. Adding, removing or changing the direction of an effect arrow means changing the set of regression equations. Path analysis tests whether or not postulated effects, based on the theory presented, correspond to the observed covariance structure of the data. Path analysis does not prove causality, but it tests whether the data set allows or denies the postulated effects. The path analysis model which had the best fit in paper I did not include a direct effect arrow from age to CSF A $\beta 42$ levels. However, the design of the path analysis model corrects for a possible relationship between these two factors, and still suggests that WML load may be associated low CSF A $\beta 42$ levels. Table 1 shows that there were no significant differences in age between patients with low and normal CSF A $\beta 42$ levels, but a significant difference in WML load which was confirmed by testing with Students ttest.

Table 1: Age and WML load of patients with pathological and normal CSF Aß42 levels in paper $\mathbf{I}$

\begin{tabular}{|l|l|l|l|l|}
\hline & $\begin{array}{l}\mathrm{A} \beta 42 \leq 450 \\
\mathrm{n}=58\end{array}$ & $\begin{array}{l}\mathrm{A} \beta 42>450 \\
\mathrm{n}=63\end{array}$ & $\begin{array}{l}\text { Mean difference } \\
(95 \% \text { CI of the difference })\end{array}$ & -value \\
\hline Age & $66.6(6.9)$ & $65.4(7.5)$ & $-1.2(-3.7 ; 1.4)$ & 0.37 \\
\hline WML load & $5.5(3.3)$ & $4.1(2.9)$ & $-1.3(-2.4 ;-0.2)$ & 0.02 \\
\hline
\end{tabular}

Numbers are mean (SD) unless otherwise given. Student's t-test.

When interpreting the results from studies investigating the relationship between WML and cognition, two important issues have to be taken under consideration:

1) What population was studied? Effects of WML on cognition in patients with cognitive impairment, as in paper II and III, may differ from effects of WML observed in a cohort of normal elderly. Also, as shown in paper II, in selected AD patients, the pronounced effects of amyloid deposition and neurofibrillar pathology 
may make the effects of WML more subtle and less easy to discern in cognitive tests. The effect of WML on cognition in the elderly has recently been reviewed (Frisoni et al., 2007). When compared to the effects of a neurodegenerative disorder such as AD, the effects are relatively small. This may explain why the effects of WML on cognition are difficult to detect in the presence of $\mathrm{AD}$.

2) What scale or method was used to quantify PV and SC WML? There are various methods to quantify PV and SC WML. In our study we defined PV WML as WML adjacent to the ventricles. If these lesions extended more than $1 \mathrm{~cm}$ away from the ventricle and further into deep white matter, the part of the WML, which was more than $1 \mathrm{~cm}$ away from the ventricle wall, was rated as SC WML. Other studies (e.g. van Straaten et al., 2008), define all WML adjacent to the ventricle wall as PV WML. This means that the WML defined as "high levels of PV WML" in the some studies would have been defined as high levels of PV and high levels of SC WML in others, even though they describe the same phenomenon: advanced WML extending from the periventricular regions into deep subcortical areas.

For assessment of cognitive function in paper II and III, the Neurobehavioral Cognitive Status Examination (Cognistat) (Kiernan et al., 1987; Schwamm et al., 1987) was used. The Cognistat is primarily a screening test, which has gained considerable popularity. Like in all test situations, anxiety and stress may cause the patient to perform worse than he/she normally would. Using experienced staff trained for the specific purpose can minimize this problem. In the memory unit at Akershus University Hospital, where the testing was conducted, the staff has many years of clinical experience, and the Cognistat test has been in use in the unit for almost a decade.

Papers I-V were all cross-sectional studies with relative small patient samples. Cross-sectional data can be used to assess the prevalence (total number of cases in a population at a given time) of acute or chronic conditions. However, cross-sectional studies are descriptive studies where cause (exposure, e.g. age, hypertension) and consequence (disease, e.g. WML, CSF A $\beta 42$ ) are measured simultaneously in a given population. A cross-sectional study therefore provides a "snapshot" of the characteristics of a measured disease or condition in a population at a given point in time. Cross-sectional studies are very useful to explore relationships between exposure and measured disease/condition. However, since exposure and disease status are measured at the same point in time, such studies can not clarify whether the 
exposure preceded or followed the disease, and therefore the relationship between exposure and disease can not be definitely established. Prospective, longitudinal studies observe the course of disease development as several measurements are performed over a period of time. Exposure to certain possible risk factors may be followed before a certain disease or condition develops. In papers I-IV the data were collected retrospectively. This obviously resulted in some missing data, making the samples smaller.

When studying acquired risk factors, as was done in paper I, a large patient cohort is needed. In paper I, only 121 patients were available for studying the relationship between acquired risk factors for cerebrovascular disease, WML and CSF A $\beta 42$. The findings therefore need to be confirmed in larger patient sample and, preferably, in a longitudinal study. However, as discussed earlier, many studies have shown that cerebrovascular disease and beta amyloid processing are somehow connected. Despite the small patient sample, paper 1 demonstrates a link between these two important factors in the development of AD.

In paper $\mathrm{V}$, the use of two different scanners with slight differences in acquisition matrices may possibly have introduced biases, but the reported effects were observed in both samples and scanner site was regressed out in all analyses so it is not likely that this introduced a systematic bias in the results. Another weakness of paper $\mathrm{V}$ was that controls were not tested formally with regard to cognitive performance. To ensure that controls are "cognitively healthy", it is important to include formal testing of the control cohorts in future studies.

According to criteria for MCI, in addition to subjective memory impairment, preserved general intellectual function, and no or very mild ADL problems, objectively verifiable memory impairment or deficits in other cognitive domains must be present (Petersen et al., 1999, Winblad et al., 2004). Patients with early cognitive deficits may fall into either GDS group 2 and 3, e.g. based on pre-morbid cognitive capacity and the fact that cutoffs for cognitive tests are group-based and not individualized. It has been suggested that AD may be identified earlier if intraindividual changes are considered rather than cutoffs based on group norms (Storandt et al., 2006). In order not to exclude patients with very early disease, patients with subjective memory complaints and clinical dementia rating $(\mathrm{CDR})=0.5$ but with screening test results above cut-off, corresponding to criteria for SCI (or GDS 2) and to "CDR 0.5/uncertain dementia" (Morris et al., 2001), were also included in paper V. 
Analysis of the entire SCI/MCI group and for the MCI group alone were performed, giving much the same results, but with lower levels of significance when excluding SCI patients from the analysis. The latter effect is likely to reflect the smaller sample size. The SCI group alone was not large enough for separate analysis.

\section{Comments}

The exact cause of white matter lesions associated with age and cognitive decline have not yet been established. As discussed, the main hypothesis is that chronic hypoperfusion of the brain and/or disruption of the blood-brain barrier are the main contributors to these changes. This is supported by molecular studies showing higher contents of hypoxia-associated proteins in WML than in normal white matter (Fernando et al., 2006). Other changes associated with WML include apoptosis of oligodendrocytes, increased microglial activation, and myelin attenuation (for discussion see Simpson et al., 2007). Oligodendrocytes comprise the largest component of white matter, their main function being the insulation of the axons. Recent studies suggest that myelinating processes of oligodendrocytes contain NMethyl-D-aspartate (NMDA) receptors, which render them sensitive to damage when extra cellular glutamate is released during ischemia (Káradóttir et al., 2005). More research related to molecular events during ischemia is needed, but these or similar mechanisms could help explain how hypoperfusion of the cerebral white matter could contribute to dysmyelination and white matter degeneration. The findings in paper $\mathrm{V}$ show how the combination of CSF analysis and DTI is essential to detect early white matter changes in subgroups of patients before they are visible on conventional MRI. It remains to be investigated whether these early alterations are related to cerebrovascular risk factors.

Recent research suggests many similar risk factors for degenerative and vascular cerebral disease such that there is little doubt that these disease processes are somehow related. Findings presented in this thesis likewise suggest a link between vascular and degenerative disease processes. However, it is not yet clear how events in gray and white matter are related. White matter changes seem to play an important role in the development not only of vascular, but also of degenerative cognitive impairment and dementia. As previously discussed, white matter changes have been 
observed before cortical degeneration occurs, and cerebrovascular changes are common in AD.

$\mathrm{AD}$ is considered to be a multifactorial disease where both genetic factors and cerebrovascular changes play important roles. It is easily conceivable that various pathological processes in different degrees may lead to a common final pathway. 


\section{CONCLUSIONS AND FURTHER PERSPECTIVES}

Both cerebrovascular changes and ApoE genotype are related to amyloid pathology in $C S F$

The findings presented in this thesis supports the hypothesis that there is a link between cerebrovascular disease and amyloid pathology. The age-independent relationship between WML and low CSF A $\beta 42$ levels in paper I suggests that chronic ischemia may increase the risk of developing AD pathology. Paper IV further supports this hypothesis and suggests an interaction between ischemia and genetic predisposition in the development of AD pathology. Age, hypertension and hyperhomocysteinemia are further confirmed as important risk factors for ischemic WML. Since ApoE- $\varepsilon 4$ carriers with high WML loads were found to exhibit low CSF $\mathrm{A} \beta 42$, these particular patient cohorts may benefit from early treatments of e.g. hypertension and hyperhomocysteinemia in order to prevent further disease development.

\section{White matter lesions are related to cognitive function}

This thesis also confirms that WML are associated with impairments of multiple cognitive domains, including delayed recall and executive functions. By demonstrating this relationship in a patient group without CSF findings of amyloid pathology, the hypothesis that WML alone may affect cognitive function receives considerable support. Our findings suggest that in the group with low CSF A $\beta 42$ the more subtle effects of WML may be obscured by the more predominant effects that cortical amyloid pathology may have on cognition.

\section{Subcortical WML are more strongly related to cognition than periventricular WML} An important finding of our studies was that SC WML were more strongly related to reduced cognitive function than PV WML. PV WML were observed in a younger age group than SC WML, and all patients with high loads of SC WML also had high loads of PV WML. This suggests that SC WML may represent a more advanced stage of microvascular disease than PV WML. The stronger relationship between SC WML and cognition supports the latter interpretation. 
DTI and CSF analysis are essential to differentiate early disease mechanisms

As presented in paper V, DTI combined with CSF biomarkers could be shown to be useful tools to identify early disease related changes in patients at risk of developing $\mathrm{AD}$. In these patients early pathogenetic events may be related to axonal damage in fiber tracks affecting the memory network. These observations bear on the important issue of early identification of disease processes, which need to be understood for the development of disease modifying drugs.

In summary, the results presented in this thesis add substantial new information concerning white matter changes in the human brain. Even though our findings in human subjects are by necessity descriptive and correlative, we have every reason to assume that white matter changes may contribute to the development of cognitive impairment and $\mathrm{AD}$ pathology. As all results presented in this thesis are based on cross-sectional data, our findings need to be confirmed in prospective and experimental studies.

Some objectives of further studies might include the following approaches:

I. to longitudinally study WML progression and compare this to the development of low CSF A $\beta 42$

II. to study WML progression and its relationship to cognitive decline and cortical atrophy

III. to study cerebrovascular changes in gene modified hypertensive rats and relate this to amyloid deposition, and if possible also to ApoE- $\varepsilon 4$ status

IV. to longitudinally study DTI changes in SCI/MCI patients and compare this to CSF biomarkers and cognitive decline

V. to study how early DTI changes are related to vascular risk factors

VI. to study molecular events related to ischemia and hypoperfusion 


\section{REFERENCES}

ANDREASEN N, BLENNOW K. CSF biomarkers for mild cognitive impairment and early Alzheimer's disease. Clin Neurol Neurosurg 2005;107:165-173.

ANDREASEN N, HESSE C, DAVIDSSON P et al. Cerebrospinal fluid betaamyloid(1-42) in Alzheimer disease: differences between early- and late-onset Alzheimer disease and stability during the course of disease. Arch Neurol 1999;56:673-680.

ARTERO S, TIEMEIER H, PRINS ND, SABATIER R, BRETELER MM, RITCHIE K. Neuroanatomical localisation and clinical correlates of white matter lesions in the elderly. J Neurol Neurosurg Psychiatry 2004;75:1304-1308.

AU R, MASSARO JM, WOLF PA et al. Association of white matter hyperintensity volume with decreased cognitive functioning: the Framingham Heart Study. Arch Neurol 2006;63:246-50.

AWAD IA, JOHNSON PC, SPETZLER RF, HODAK JA. Incidental subcortical lesions identified on magnetic resonance imaging in the elderly. II. Postmortem pathological correlations. Stroke 1986;17:1090-7.

BADAN I, BUCHHOLD B, HAMM A et al. Accelerated glial reactivity to stroke in aged rats correlates with reduced functional recovery. J Cereb Blood Flow Metab 2003;23:845-854.

BAEZNER H, BLAHAK C, POGGESI A et al. Association of gait and balance disorders with age-related white matter changes: the LADIS study. Neurology 2008;70:935-42.

BALES KR, VERINA T, DODEL RC et al. Lack of apolipoprotein E dramatically reduces amyloid beta-peptide deposition. Nat Genet 1997;17:263-264.

BASSER PJ, MATTIELLO J, LEBIHAN D. MR diffusion tensor spectroscopy and imaging. Biophys J 1994;66:259-267.

BASSER PJ. Inferring microstructural features and the physiological state of tissues from diffusion-weighted images. NMR Biomed 1995;8:333-344.

BAUM KA, SCHULTE C, GIRKE W, REISCHIES FM, FELIX R. Incidental whitematter foci on MRI in "healthy" subjects: evidence of subtle cognitive dysfunction. Neuroradiology 1996;38:755-60. 
BERTSCH T, MIELKE O, HOLY S et al. Homocysteine in cerebrovascular disease: an independent risk factor for subcortical vascular encephalopathy. Clin Chem Lab Med 2001;39:721-724.

BLENNOW K, DE LEON MJ, ZETTERBERG H. Alzheimer's disease. Lancet 2006;368:387-403.

BLENNOW K, HAMPEL H. CSF markers for incipient Alzheimer's disease. Lancet Neurol 2003;2:605-13.

BOLLEN KA. Structural equations with latent variables. New York: Wiley, 1989.

BOUWMAN FH, SCHOONENBOOM NS, VERWEY NA et al. CSF biomarker levels in early and late onset Alzheimer's disease. Neurobiol Aging 2008; Epub ahead of print.

BRAAK E, GRIFFING K, ARAI K, BOHL J, BRATZKE H, BRAAK H. Neuropathology of Alzheimer's disease: what is new since A. Alzheimer? Eur Arch Psychiatry Clin Neurosci 1999;249 Suppl 3:14-22.

BRETELER MM, VAN SWIETEN JC, BOTS ML et al. Cerebral white matter lesions, vascular risk factors, and cognitive function in a population-based study: the Rotterdam Study. Neurology 1994;44:1246-1252.

BRODAL P. The central nervous system: structure and function. 2nd ed. New York: Oxford University Press; 1998.

BRONGE L, FERNAEUS SE, BLOMBERG $\mathrm{M}$ et al. White matter lesions in Alzheimer patients are influenced by apolipoprotein E genotype. Dement Geriatr Cogn Disord 1999;10:89-96.

BROOKMEYER R, JOHNSON E, ZIEGLER-GRAHAM K et al. Forecasting the global burden of Alzheimer's disease. Baltimore, USA: The Berkeley Electronic Press; 2007

BUCKNER RL, SNYDER AZ, SHANNON BJ et al. Molecular, structural, and functional characterization of Alzheimer's disease: evidence for a relationship between default activity, amyloid, and memory. J Neurosci 2005;25:7709-17.

BUDDE MD, KIM JH, LIANG HF et al. Toward accurate diagnosis of white matter pathology using diffusion tensor imaging. Magn Reson Med 2007;57:688-695.

BURNS JM, CHURCH JA, JOHNSON DK et al. White matter lesions are prevalent but differentially related with cognition in aging and early Alzheimer disease. Arch Neurol 2005;62:1870-6. 
CARMELLI D, DECARLI C, SWAN GE et al. Evidence for genetic variance in white matter hyperintensity volume in normal elderly male twins. Stroke 1998;29:1177-1181.

CASSERLY I, TOPOL E. Convergence of atherosclerosis and Alzheimer's disease: inflammation, cholesterol, and misfolded proteins. Lancet 2004;363(9415):1139-1146.

CATANI M, FFYTCHE DH. The rises and falls of disconnection syndromes. Brain 2005; 128:2224-39.

CATANI M, HOWARD RJ, PAJEVIC S, JONES DK. Virtual in vivo interactive dissection of white matter fasciculi in the human brain. Neuroimage 2002; 17:77-94.

CHALMERS K, WILCOCK G, LOVE S. Contributors to white matter damage in the frontal lobe in Alzheimer's disease. Neuropathol Appl Neurobiol 2005;31:62331.

CHARLTON RA, BARRICK TR, MCINTYRE DJ et al. White matter damage on diffusion tensor imaging correlates with age-related cognitive decline. Neurology 2006;66:217-222.

CHOI SJ, LIM KO, MONTEIRO I, REISBERG B. Diffusion tensor imaging of frontal white matter microstructure in early Alzheimer's disease: a preliminary study. J Geriatr Psychiatry Neurol 2005;18:12-19.

CONCHA L, GROSS DW, WHEATLEY BM, BEAULIEU C. Diffusion tensor imaging of time-dependent axonal and myelin degradation after corpus callosotomy in epilepsy patients. Neuroimage 2006;32:1090-1099.

CONVIT A, DE LEON MJ, TARSHISH C et al. Specific hippocampal volume reductions in individuals at risk for Alzheimer's disease. Neurobiol Aging 1997; 18:131-138.

CORDER EH, SAUNDERS AM, STRITTMATTER WJ et al. Gene dose of apolipoprotein E type 4 allele and the risk of Alzheimer's disease in late onset families. Science 1993;261:921-923.

CROSBY EC, HUMPHREY, T., LAUER, E.W. Correlative Anatomy of the Nervous System. 1st ed. New York: The Macmillian Company; 1962.

DE GROOT JC, DE LEEUW FE, OUDKERK M et al. Cerebral white matter lesions and cognitive function: the Rotterdam Scan Study. Ann Neurol 2000;47:14551. 
DE GROOT JC, DE LEEUW FE, OUDKERK M et al. Cerebral white matter lesions and depressive symptoms in elderly adults. Arch Gen Psychiatry 2000;57:1071-6.

DE LA MONTE SM. Quantitation of cerebral atrophy in preclinical and end-stage Alzheimer's disease. Ann Neurol 1989;25:450-459.

DE LA TORRE JC. Alzheimer disease as a vascular disorder: nosological evidence. Stroke 2002;33(4):1152-1162.

DE LEEUW FE, BARKHOF F, SCHELTENS P. White matter lesions and hippocampal atrophy in Alzheimer's disease. Neurology 2004;62:310-312.

DE LEEUW FE, DE KLEINE M, FRIJNS CJ, FIJNHEER R, VAN GIJN J,

KAPPELLE LJ. Endothelial cell activation is associated with cerebral white matter lesions in patients with cerebrovascular disease. Ann N Y Acad Sci 2002;977:306-14.

DE LEON MJ, MOSCONI L, BLENNOW K et al. Imaging and CSF studies in the preclinical diagnosis of Alzheimer's disease. Ann N Y Acad Sci 2007;1097:114-145.

DE REUCK J. The human periventricular arterial blood supply and the anatomy of cerebral infarctions. Eur Neurol 1971;5:321-34.

DECARLI C, FLETCHER E, RAMEY V, HARVEY D, JAGUST WJ. Anatomical mapping of white matter hyperintensities (WMH): exploring the relationships between periventricular WMH, deep WMH, and total WMH burden. Stroke 2005;36:50-5.

DECARLI C, MURPHY DG, TRANH M et al. The effect of white matter hyperintensity volume on brain structure, cognitive performance, and cerebral metabolism of glucose in 51 healthy adults. Neurology 1995;45:2077-84.

DEKOSKY ST, MAREK K. Looking backward to move forward: early detection of neurodegenerative disorders. Science 2003;302:830-834.

DELANO-WOOD L, ABELES N, SACCO JM, WIERENGA CE, HORNE NR, BOZOKI A. Regional white matter pathology in mild cognitive impairment: differential influence of lesion type on neuropsychological functioning. Stroke 2008;39:794-9.

DEO AA, GRILL RJ, HASAN KM, NARAYANA PA. In vivo serial diffusion tensor imaging of experimental spinal cord injury. J Neurosci Res 2006;83:801-810. 
DINIZ BS, PINTO JA, JR., FORLENZA OV. Do CSF total tau, phosphorylated tau, and beta-amyloid 42 help to predict progression of mild cognitive impairment to Alzheimer's disease? A systematic review and meta-analysis of the literature. World J Biol Psychiatry 2007;1-11.

DRUBIN D, KOBAYASHI S, KELLOGG D, KIRSCHNER M. Regulation of microtubule protein levels during cellular morphogenesis in nerve growth factor-treated PC12 cells. J Cell Biol 1988;106:1583-1591.

DU AT, SCHUFF N, AMEND D et al. Magnetic resonance imaging of the entorhinal cortex and hippocampus in mild cognitive impairment and Alzheimer's disease. J Neurol Neurosurg Psychiatry 2001;71:441-447.

DUBOIS B, FELDMAN HH, JACOVA C et al. Research criteria for the diagnosis of Alzheimer's disease: revising the NINCDS-ADRDA criteria. Lancet Neurol 2007;6:734-46.

EHEHALT R, KELLER P, HAASS C, THIELE C, SIMONS K. Amyloidogenic processing of the Alzheimer beta-amyloid precursor protein depends on lipid rafts. J Cell Biol 2003;160:113-123.

EICHNER JE, DUNN ST, PERVEEN G, THOMPSON DM, STEWART KE, STROEHLA BC. Apolipoprotein E polymorphism and cardiovascular disease: a HuGE review. Am J Epidemiol 2002;155:487-495.

ENGLUND E. Neuropathology of white matter changes in Alzheimer's disease and vascular dementia. Dement Geriatr Cogn Disord 1998;9 Suppl 1:6-12.

ENGLUND E. Neuropathology of white matter lesions in vascular cognitive impairment. Cerebrovasc Dis 2002;13 Suppl 2:11-5.

FAGAN AM, MINTUN MA, MACH RH et al. Inverse relation between in vivo amyloid imaging load and cerebrospinal fluid Abeta42 in humans. Ann Neurol 2006;59:512-9.

FARRER LA, CUPPLES LA, HAINES JL et al. Effects of age, sex, and ethnicity on the association between apolipoprotein E genotype and Alzheimer disease. A meta-analysis. APOE and Alzheimer Disease Meta Analysis Consortium. JAMA 1997;278:1349-1356.

FASSBENDER K, SIMONS M, BERGMANN C et al. Simvastatin strongly reduces levels of Alzheimer's disease beta -amyloid peptides Abeta 42 and Abeta 40 in vitro and in vivo. Proc Natl Acad Sci U S A 2001;98(10):5856-5861. 
FAZEKAS F, CHAWLUK JB, ALAVI A, HURTIG HI, ZIMMERMAN RA. MR signal abnormalities at $1.5 \mathrm{~T}$ in Alzheimer's dementia and normal aging. AJR Am J Roentgenol 1987;149:351-6.

FAZEKAS F, KLEINERT R, OFFENBACHER H et al. Pathologic correlates of incidental MRI white matter signal hyperintensities. Neurology 1993;43:16839.

FELLGIEBEL A, MULLER MJ, WILLE P et al. Color-coded diffusion-tensorimaging of posterior cingulate fiber tracts in mild cognitive impairment. Neurobiol Aging 2005;26:1193-1198.

FERNANDO MS, SIMPSON JE, MATTHEWS F et al. White matter lesions in an unselected cohort of the elderly: molecular pathology suggests origin from chronic hypoperfusion injury. Stroke 2006;37:1391-1398.

FLADBY T, MAEHLEN J. The amyloid and tau hypothesis in degenerative dementia. Tidsskr Nor Laegeforen 1999;119:976-9.

FOLSTEIN MF, FOLSTEIN SE, MCHUGH PR. "Mini-mental state". A practical method for grading the cognitive state of patients for the clinician. J Psychiatr Res 1975;12:189-98.

FORETTE F, SEUX ML, STAESSEN JA et al. The prevention of dementia with antihypertensive treatment: new evidence from the Systolic Hypertension in Europe (Syst-Eur) study. Arch Intern Med 2002;162:2046-2052.

FORMICHI P, PARNETTI L, RADI E, CEVENINI G, DOTTI MT, FEDERICO A. CSF levels of beta-amyloid 1-42, tau and phosphorylated tau protein in CADASIL. Eur J Neurol 2008;15:1252-5.

FORSBERG A, ENGLER H, ALMKVIST O et al. PET imaging of amyloid deposition in patients with mild cognitive impairment. Neurobiol Aging 2007;29:1456-65.

FRISONI GB, GALLUZZI S, PANTONI L, FILIPPI M. The effect of white matter lesions on cognition in the elderly--small but detectable. Nat Clin Pract Neurol 2007;3:620-7.

GEORGE R, GRIFFIN JW. Delayed macrophage responses and myelin clearance during Wallerian degeneration in the central nervous system: the dorsal radiculotomy model. Exp Neurol 1994a;129:225-236.

GEORGE R, GRIFFIN JW. The proximo-distal spread of axonal degeneration in the dorsal columns of the rat. J Neurocytol 1994b;23:657-667. 
GOLD G, KOVARI E, HOF PR, BOURAS C, GIANNAKOPOULOS P. Sorting out the clinical consequences of ischemic lesions in brain aging: a clinicopathological approach. J Neurol Sci 2007;257:17-22.

GORELICK PB. Risk factors for vascular dementia and Alzheimer disease. Stroke 2004;35:2620-2622.

GREEN MS, KAYE JA, BALL MJ. The Oregon Brain Aging Study: neuropathology accompanying healthy aging in the oldest old. Neurology 2000;54:105-13.

GRUNDKE-IQBAL I, IQBAL K, TUNG YC et al. Abnormal phosphorylation of the microtubule-associated protein $\tau$ (tau) in Alzheimer cytoskeletal pathology. Proc Natl Acad Sci 1986;83:4913-17.

GUROL ME, IRIZARRY MC, SMITH EE et al. Plasma beta-amyloid and white matter lesions in $\mathrm{AD}, \mathrm{MCI}$, and cerebral amyloid angiopathy. Neurology 2006;66:23-29

HACHINSKI VC, POTTER P, MERSKEY H. Leuko-araiosis. Arch Neurol $1987 ; 44: 21-23$.

HAMPEL H, TEIPEL SJ, FUCHSBERGER T et al. Value of CSF beta-amyloid1-42 and tau as predictors of Alzheimer's disease in patients with mild cognitive impairment. Mol Psychiatry 2004;9:705-710.

HANSSON O, ZETTERBERG H, BUCHHAVE P, LONDOS E, BLENNOW K, MINTHON L. Association between CSF biomarkers and incipient Alzheimer's disease in patients with mild cognitive impairment: a follow-up study. Lancet Neurol 2006;5:228-234.

HERZ J, BEFFERT U. Apolipoprotein E receptors: linking brain development and Alzheimer's disease. Nat Rev Neurosci 2000;1:51-58.

HESSE C, ROSENGREN L, VANMECHELEN E et al. Cerebrospinal fluid markers for Alzheimer's disease evaluated after acute ischemic stroke. J Alzheimer Dis 2000;2:199-206.

HOLTZMAN DM, FAGAN AM, MACKEY B et al. Apolipoprotein E facilitates neuritic and cerebrovascular plaque formation in an Alzheimer's disease model. Ann Neurol 2000;47:739-747.945.

HUANG J, AUCHUS AP. Diffusion tensor imaging of normal appearing white matter and its correlation with cognitive functioning in mild cognitive impairment and Alzheimer's disease. Ann N Y Acad Sci 2007;1097:259-64. 
HUANG J, FRIEDLAND RP, AUCHUS AP. Diffusion tensor imaging of normalappearing white matter in mild cognitive impairment and early Alzheimer disease: preliminary evidence of axonal degeneration in the temporal lobe. AJNR Am J Neuroradiol 2007;28:1943-1948.

HUNT AL, ORRISON WW, YEO RA et al. Clinical significance of MRI white matter lesions in the elderly. Neurology 1989;39:1470-4.

HY LX, KELLER DM. Prevalence of AD among whites: a summary by levels of severity. Neurology 2000;55:198-204.

INZITARI D, MASCALCHI M. Leuko-araiosis: a reappraisal. I. CT studies. Ital J Neurol Sci 1990;11:241-248.

INZITARI D. Age-related white matter changes and cognitive impairment. Ann Neurol 2000;47:141-3.

IQBAL K, ALONSO ADEL C, CHEN S. Tau pathology in Alzheimer disease and other tauopathies. Biochim Biophys Acta 2005;1739:198-210.

JACK CR, JR., PETERSEN RC, XU YC et al. Prediction of AD with MRI-based hippocampal volume in mild cognitive impairment. Neurology 1999;52:13971403.

JENDROSKA K, POEWE W, DANIEL SE et al. Ischemic stress induces deposition of amyloid beta immunoreactivity in human brain. Acta Neuropathol (Berl) 1995;90:461-66.

JIA JP, MENG R, SUN YX, SUN WJ, JI XM, JIA LF. Cerebrospinal fluid tau, Abeta1-42 and inflammatory cytokines in patients with Alzheimer's disease and vascular dementia. Neurosci Lett 2005;383:12-16.

JIN K, MAO XO, ESHOO MW et al. Microarray analysis of hippocampal gene expression in global cerebral ischemia. Ann Neurol 2001;50:93-103.

JOKINEN H, KALSKA H, MANTYLA R et al. Cognitive profile of subcortical ischaemic vascular disease. J Neurol Neurosurg Psychiatry 2006;77:28-33.

JONES DK, LYTHGOE D, HORSFIELD MA, SIMMONS A, WILLIAMS SC, MARKUS HS. Characterization of white matter damage in ischemic leukoaraiosis with diffusion tensor MRI. Stroke 1999;30:393-7.

KÁRADÓTTIR R, CAVELIER P, BERGERSEN LH, ATTWELL D. NMDA receptors are expressed in oligodendrocytes and activated in ischaemia. Nature 2005;438:1162-1166. 
KAWARABAYASHI T, YOUNKIN LH, SAIDO TC, SHOJI M, ASHE KH, YOUNKIN SG. Age-dependent changes in brain, CSF, and plasma amyloid (beta) protein in the Tg2576 transgenic mouse model of Alzheimer's disease. J Neurosci 2001;21:372-381.

KIERNAN RJ, MUELLER J, LANGSTON JW, VAN DYKE C. The Neurobehavioral Cognitive Status Examination: a brief but quantitative approach to cognitive assessment. Ann Intern Med 1987;107:481-5.

KNOPMAN DS, PARISI JE, SALVIATI A et al. Neuropathology of cognitive normal elderly. J Neuropathol Exp Neurol 2003;62:1087-95.

LAZARUS R, PRETTYMAN R, CHERRYMAN G. White matter lesions on magnetic resonance imaging and their relationship with vascular risk factors in memory clinic attenders. Int J Geriatr Psychiatry 2005;20:274-9.

LE BIHAN D, MANGIN JF, POUPON C et al. Diffusion tensor imaging: concepts and applications. J Magn Reson Imaging 2001;13:534-546.

LEYS D, PRUVO JP, PARENT M et al. Could Wallerian degeneration contribute to "leuko-araiosis" in subjects free of any vascular disorder? J Neurol Neurosurg Psychiatry 1991;54:46-50.

LIM GP, CALON F, MORIHARA T et al. A diet enriched with the omega-3 fatty acid docosahexaenoic acid reduces amyloid burden in an aged Alzheimer mouse model. J Neurosci 2005;25:3032-3040.

LONGSTRETH WT, JR., MANOLIO TA, ARNOLD A et al. Clinical correlates of white matter findings on cranial magnetic resonance imaging of 3301 elderly people. The Cardiovascular Health Study. Stroke 1996;27:1274-82.

MASANA Y, MOTOZAKI T. Emergence and progress of white matter lesion in brain check-up. Acta Neurol Scand 2003;107:187-194.

MCCARRON MO, DELONG D, ALBERTS MJ. APOE genotype as a risk factor for ischemic cerebrovascular disease: a meta-analysis. Neurology 1999;53:13081311.

MELTON LM, KEITH AB, DAVIS S, OAKLEY AE, EDWARDSON JA, MORRIS CM. Chronic glial activation, neurodegeneration, and APP immunoreactive deposits following acute administration of double-stranded RNA. Glia 2003;44:1-12.

MEYER JS, KAWAMURA J, TERAYAMA Y. White matter lesions in the elderly. J Neurol Sci 1992;110:1-7. 
MOLLENHAUER B, CEPEK L, BIBL M et al. Tau protein, Abeta42 and S-100B protein in cerebrospinal fluid of patients with dementia with Lewy bodies. Dement Geriatr Cogn Disord 2005;19:164-170.

MORRIS JC, STORANDT M, MILLER JP et al. Mild cognitive impairment represents early-stage Alzheimer disease. Arch Neurol 2001;58:397-405.

MOSCONI L. Brain glucose metabolism in the early and specific diagnosis of Alzheimer's disease: FDG-PET studies in MCI and AD. Eur J Nucl Med Mol Imaging 2005;32:486-510.

MURAKAMI N, YAMAKI T, IWAMOTO Y et al. Experimental brain injury induces expression of amyloid precursor protein, which may be related to neuronal loss in the hippocampus. J Neurotrauma 1998;15:993-1003.

NAPOLI C, PALINSKI W. Neurodegenerative diseases: insights into pathogenic mechanisms from atherosclerosis. Neurobiol Aging 2005;26:293-302.

NIHASHI T, INAO S, KAJITA Y et al. Expression and distribution of beta amyloid precursor protein and beta amyloid peptide in reactive astrocytes after transient middle cerebral artery occlusion. Acta Neurochir (Wien) 2001;143:287-295.

NOGUCHI M, YOSHITA M, MATSUMOTO Y, ONO K, IWASA K, YAMADA M. Decreased beta-amyloid peptide42 in cerebrospinal fluid of patients with progressive supranuclear palsy and corticobasal degeneration. J Neurol Sci 2005;237:61-65.

NORDAHL CW, RANGANATH C, YONELINAS AP, DECARLI C, FLETCHER E, JAGUST WJ. White matter changes compromise prefrontal cortex function in healthy elderly individuals. J Cogn Neurosci 2006;18:418-29.

O'SULLIVAN M, SUMMERS PE, JONES DK et al. Normal-appearing white matter in ischemic leukoaraiosis: A diffusion tensor MRI study. Neurology 2001;57:2307-2310.

O'SULLIVAN M, MORRIS RG, HUCKSTEP B, JONES DK, WILLIAMS SC, MARKUS HS. Diffusion tensor MRI correlates with executive dysfunction in patients with ischaemic leukoaraiosis. J Neurol Neurosurg Psychiatry 2004; 75:441-7.

O'SULLIVAN M. Leukoaraiosis. Pract Neurol 2008;8:26-38. 
OTTO M, ESSELMANN H, SCHULZ-SHAEFFER W et al. Decreased betaamyloid1-42 in cerebrospinal fluid of patients with Creutzfeldt-Jakob disease. Neurology 2000;54:1099-1102.

OTTO M, WILTFANG J, TUMANI H et al. Elevated levels of tau-protein in cerebrospinal fluid of patients with Creutzfeldt-Jakob disease. Neurosci Lett 1997;225:210-2.

PANTONI L, GARCIA JH. The significance of cerebral white matter abnormalities 100 years after Binswanger's report. A review. Stroke 1995;26:1293-1301.

PANTONI L, POGGESI A, BASILE AM et al. Leukoaraiosis predicts hidden global functioning impairment in nondisabled older people: the LADIS (Leukoaraiosis and Disability in the Elderly) Study. J Am Geriatr Soc 2006;54:1095-101.

PANTONI L. Pathophysiology of age-related cerebral white matter changes.

Cerebrovasc Dis 2002;13 Suppl 2:7-10.

PAPEZ JW. A proposed mechanism of emotion. 1937. J Neuropsychiatry Clin Neurosci 1995;7:103-112.

PESKIND ER, LI G, SHOFER J et al. Age and apolipoprotein E*4 allele effects on cerebrospinal fluid beta-amyloid 42 in adults with normal cognition. Arch Neurol 2006;63:936-9.

PETERSEN RC, DOODY R, KURZ A et al. Current concepts in mild cognitive impairment. Arch Neurol 2001;58:1985-1992.

PETERSEN RC, SMITH GE, WARING SC, IVNIK RJ, TANGALOS EG, KOKMEN E. Mild cognitive impairment: clinical characterization and outcome. Arch Neurol 1999;56:303-308.

PETERSEN RC. Mild cognitive impairment as a diagnostic entity. J Intern Med 2004;256:183-194.

PIERPAOLI C, BARNETT A, PAJEVIC S et al. Water diffusion changes in Wallerian degeneration and their dependence on white matter architecture. Neuroimage 2001;13:1174-1185.

PRINS ND, DEN HEIJER T, HOFMAN A et al. Homocysteine and cognitive function in the elderly: the Rotterdam Scan Study. Neurology 2002;59:13751380 . 
PRINS ND, VAN DIJK EJ, DEN HEIJER T et al. Cerebral small-vessel disease and decline in information processing speed, executive function and memory. Brain 2005;128:2034-41.

PRINS ND, VAN DIJK EJ, DEN HEIJER T et al. Cerebral white matter lesions and the risk of dementia. Arch Neurol 2004;61:1531-1534.

REBECK GW. Cholesterol Efflux as a Critical Component of Alzheimer's Disease Pathogenesis. Journal of Molecular Neuroscience 2004;23:219-224.

REED BR, MUNGAS DM, KRAMER JH, et al. Profiles of neuropsychological impairment in autopsy-defined Alzheimer's disease and cerebrovascular disease. Brain 2007;130:731-9.

REISBERG B, FERRIS SH, DE LEON MJ, CROOK T. Global Deterioration Scale (GDS). Psychopharmacol Bull 1988;24:661-3.

REISBERG B, GAUTHIER S. Current evidence for subjective cognitive impairment (SCI) as the pre-mild cognitive impairment (MCI) stage of subsequently manifest Alzheimer's disease. Int Psychogeriatr 2008;20:1-16.

ROHER AE, WEISS N, KOKJOHN TA et al. Increased A beta peptides and reduced cholesterol and myelin proteins characterize white matter degeneration in Alzheimer's disease. Biochemistry 2002;41:11080-11090.

ROMAN GC, ERKINJUNTTI T, WALLIN A, PANTONI L, CHUI HC. Subcortical ischaemic vascular dementia. Lancet Neurol 2002;1:426-36.

ROMAN GC, SACHDEV P, ROYALL DR et al. Vascular cognitive disorder: a new diagnostic category updating vascular cognitive impairment and vascular dementia. J Neurol Sci 2004;226:81-7.

ROMAN GC. Vascular dementia may be the most common form of dementia in the elderly. J Neurol Sci 2002;203-204:7-10.

SABRI O, RINGELSTEIN EB, HELLWIG D et al. Neuropsychological impairment correlates with hypoperfusion and hypometabolism but not with severity of white matter lesions on MRI in patients with cerebral microangiopathy. Stroke 1999;30:556-66.

SACHDEV P, PARSLOW R, SALONIKAS C et al. Homocysteine and the brain in midadult life: evidence for an increased risk of leukoaraiosis in men. Arch Neurol 2004;61:1369-1376. 
SADOWSKI M, PANKIEWICZ J, SCHOLTZOVA H et al. Links between the pathology of Alzheimer's disease and vascular dementia. Neurochem Res 2004;29:1257-66.

SALAMON G, BOUDOURESQUES J, COMBALBERT A, KHALIL R, FAURE J, GIUDICELLI G. [Lenticulo-striated arteries. Arteriographic study. Their importance in the diagnosis of intracerebral hematomas]. Rev Neurol (Paris) $1966 ; 114: 361-73$.

SALAT DH, TUCH DS, VAN DER KOUWE AJ et al. White matter pathology isolates the hippocampal formation in Alzheimer's disease. Neurobiol Aging 2008; epub ahead of print.

SAWADA H, UDAKA F, IZUMI Y et al. Cerebral white matter lesions are not associated with apoE genotype but with age and female sex in Alzheimer's disease. J Neurol Neurosurg Psychiatry 2000;68:653-656.

SCHELTENS P, BARKHOF F, LEYS D et al. A semiquantative rating scale for the assessment of signal hyperintensities on magnetic resonance imaging. $\mathrm{J}$ Neurol Sci 1993;114:7-12.

SCHWAMM LH, VAN DYKE C, KIERNAN RJ, MERRIN EL, MUELLER J. The Neurobehavioral Cognitive Status Examination: comparison with the Cognitive Capacity Screening Examination and the Mini-Mental State Examination in a neurosurgical population. Ann Intern Med 1987;107:486491.

SELKOE DJ. Deciphering the genesis and fate of amyloid-protein yields novel therapies for Alzheimer disease. J Clin Invest 2002;110:1375-1381.

SIMPSON JE, FERNANDO MS, CLARK L et al. White matter lesions in an unselected cohort of the elderly: astrocytic, microglial and oligodendrocyte precursor cell responses. Neuropathol Appl Neurobiol 2007;33:410-419.

SJOGREN M, DAVIDSSON P, WALLIN A et al. Decreased CSF-beta-amyloid 42 in Alzheimer's disease and amyotrophic lateral sclerosis may reflect mismetabolism of beta-amyloid induced by disparate mechanisms. Dement Geriatr Cogn Disord 2002;13:112-118.

SKINNINGSRUD A, STENSET V, GUNDERSEN AS et al. Cerebrospinal fluid markers in Creutzfeldt-Jakob disease. Cerebrospinal Fluid Research $2008 ; 5: 14$ 
SNOWDON DA, GREINER LH, MORTIMER JA, RILEY KP, GREINER PA, MARKESBERY WR. Brain infarction and the clinical expression of Alzheimer disease. The Nun Study. Jama 1997;277:813-817.

SODERLUND H, NILSSON LG, BERGER K et al. Cerebral changes on MRI and cognitive function: the CASCADE study. Neurobiol Aging 2006;27:16-23.

SONG SK, SUN SW, JU WK, LIN SJ, CROSS AH, NEUFELD AH. Diffusion tensor imaging detects and differentiates axon and myelin degeneration in mouse optic nerve after retinal ischemia. Neuroimage 2003;20:1714-1722.

SONG SK, SUN SW, RAMSBOTTOM MJ, CHANG C, RUSSELL J, CROSS AH. Dysmyelination revealed through MRI as increased radial (but unchanged axial) diffusion of water. Neuroimage 2002;17:1429-1436.

STEFANI A, BERNARDINI S, PANELLA M et al. AD with subcortical white matter lesions and vascular dementia: CSF markers for differential diagnosis. $\mathrm{J}$ Neurol Sci 2005;237:83-88.

STORANDT M, GRANT EA, MILLER JP, MORRIS JC. Longitudinal course and neuropathologic outcomes in original vs revised MCI and in pre-MCI. Neurology 2006;67:467-473.

STRITTMATTER WJ, WEISGRABER KH, HUANG DY et al. Binding of human apolipoprotein E to synthetic amyloid beta peptide: isoform-specific effects and implications for late-onset Alzheimer disease. Proc Natl Acad Sci USA 1993;90:8098-8102.

STROZYK D, BLENNOW K, WHITE LR, LAUNER LJ. CSF Abeta 42 levels correlate with amyloid-neuropathology in a population-based autopsy study. Neurology 2003;60:652-656.

SUN SW, LIANG HF, CROSS AH, SONG SK. Evolving Wallerian degeneration after transient retinal ischemia in mice characterized by diffusion tensor imaging. Neuroimage 2008;40:1-10.

SUN X, HE G, QING H et al. Hypoxia facilitates Alzheimer's disease pathogenesis by up-regulating BACE1 gene expression. Proc Natl Acad Sci USA 2006;103:18727-32.

SUNDERLAND T, LINKER G, MIRZA N et al. Decreased beta-amyloid1-42 and increased tau levels in cerebrospinal fluid of patients with Alzheimer disease. Jama 2003;289:2094-2103. 
SUSSMUTH SD, REIBER H, TUMANI H. Tau protein in cerebrospinal fluid (CSF):

a blood-CSF barrier related evaluation in patients with various neurological diseases. Neurosci Lett 2001;300:95-98.

TAYLOR WD, BAE JN, MACFALL JR et al. Widespread effects of hyperintense lesions on cerebral white matter structure. AJR Am J Roentgenol 2007;188:1695-1704.

TEDESCHI G, CIRILLO M, TESSITORE A, CIRILLO S. Alzheimer's disease and other dementing conditions. Neurol Sci 2008;29 Suppl 3:301-307.

TEODORCZUK A, O'BRIEN JT, FIRBANK MJ et al. White matter changes and late-life depressive symptoms: longitudinal study. Br J Psychiatry 2007;191:212-217.

TEUNISSEN CE, DIJKSTRA C, POLMAN C. Biological markers in CSF and blood for axonal degeneration in multiple sclerosis. Lancet Neurol 2005;4:32-41.

TURNER ST, FORNAGE M. Genetics of leukoaraiosis. J Stroke Cerebrovasc Dis 2002;11:241-251.

ULUG AM , MOORE DF, BOJKO AS et al. Clinical Use of Diffusion-Tensor Imaging for Diseases Causing Neuronal and Axonal Damage. Am J Neuroradiol 1999;20:1044-1048.

VAN STRAATEN EC, HARVEY D, SCHELTENS P et al. Periventricular white matter hyperintensities increase the likelihood of progression from amnestic mild cognitive impairment to dementia. J Neurol 2008;255:1302-8.

VAN SWIETEN JC, VAN DEN HOUT JH, VAN KETEL BA, HIJDRA A, WOKKE JH, VAN GIJN J. Periventricular lesions in the white matter on magnetic resonance imaging in the elderly. A morphometric correlation with arteriolosclerosis and dilated perivascular spaces. Brain 1991;114:761-74.

VERMEER SE, PRINS ND, DEN HEIJER T, HOFMAN A, KOUDSTAAL PJ, BRETELER MM. Silent brain infarcts and the risk of dementia and cognitive decline. N Engl J Med 2003;348:1215-22.

VERMEER SE, VAN DIJK EJ, KOUDSTAAL PJ et al. Homocysteine, silent brain infarcts, and white matter lesions: The Rotterdam Scan Study. Ann Neurol 2002;51:285-289.

VERNY M, DUYCKAERTS C, PIEROT L, HAUW JJ. Leuko-araiosis. Dev Neurosci 1991;13:245-250. 
WAHLUND LO, BARKHOF F, FAZEKAS F et al. A new rating scale for agerelated white matter changes applicable to MRI and CT. Stroke 2001;32:131822.

WALLIN A, SJOGREN M, EDMAN A, BLENNOW K, REGLAND B. Symptoms, vascular risk factors and blood-brain barrier function in relation to $\mathrm{CT}$ whitematter changes in dementia. Eur Neurol 2000;44:229-235.

WALSH DM, SELKOE DJ. Deciphering the molecular basis of memory failure in Alzheimer's disease. Neuron 2004;44:181-193.

WANG S, WU EX, TAM CN, LAU HF, CHEUNG PT, KHONG PL. Characterization of white matter injury in a hypoxic-ischemic neonatal rat model by diffusion tensor MRI. Stroke 2008;39:2348-2353.

WARD NS, BROWN MM. LEUKOARAIOSIS. IN: DONNAN GA, NORRVING B., BAMFORD J, BOGOUSSLASKY J., editors. Subcortical Stroke. 2nd ed. Oxford: Oxford University Press; 2002. p. 47-66.

WILTFANG J, LEWCZUK P, RIEDERER P et al. Consensus paper of the WFSBP Task Force on Biological Markers of Dementia: the role of CSF and blood analysis in the early and differential diagnosis of dementia. World J Biol Psychiatry 2005;6:69-84.

WINBLAD B, PALMER K, KIVIPELTO M et al. Mild cognitive impairment-beyond controversies, towards a consensus: report of the International Working Group on Mild Cognitive Impairment. J Intern Med 2004;256:240246.

WISNIEWSKI T, GOLABEK A, MATSUBARA E, GHISO J, FRANGIONE B. Apolipoprotein E: binding to soluble Alzheimer's beta-amyloid. Biochem Biophys Res Commun 1993;192:359-365.

WOLOZIN B. Cholesterol and the biology of Alzheimer's disease. Neuron 2004;41:710.

WORLD HEALTH ORGANIZATION ICD-10. Online 2007; http://www.who.int/classifications/icd/en

XUE R, VAN ZIJL PC, CRAIN BJ, SOLAIYAPPAN M, MORI S. In vivo threedimensional reconstruction of rat brain axonal projections by diffusion tensor imaging. Magn Reson Med 1999;42:1123-1127.

YAM PS, PATTERSON J, GRAHAM DI, TAKASAGO T, DEWAR D, MCCULLOCH J. Topographical and quantitative assessment of white matter 
injury following a focal ischaemic lesion in the rat brain. Brain Res Brain Res Protoc 1998;2:315-322.

YIP AG, MCKEE AC, GREEN RC et al. APOE, vascular pathology, and the AD brain. Neurology 2005;65:259-265.

ZHANG Y, SCHUFF N, JAHNG GH et al. Diffusion tensor imaging of cingulum fibers in mild cognitive impairment and Alzheimer disease. Neurology 2007;68:13-19.

ZHOU Y, DOUGHERTY JH JR, HUBNER KF et al. Abnormal connectivity in the posterior cingulate and hippocampus in early Alzheimer's disease and mild cognitive impairment. Alzheimers Dement 2008;4:265-270. 


\section{ERRATA}

Page 35, 3rd paragraph: "included" has been replaced by "include" 

This article is removed. 


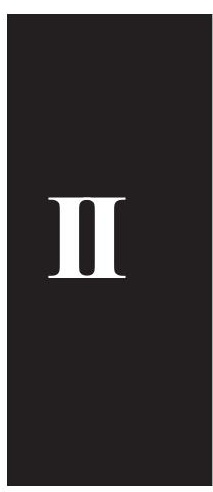


This article is removed. 


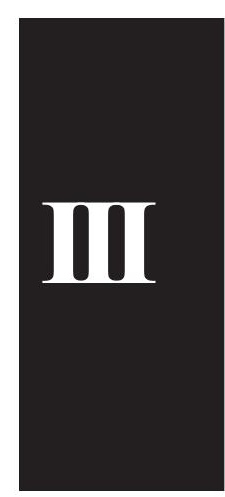


This article is removed. 


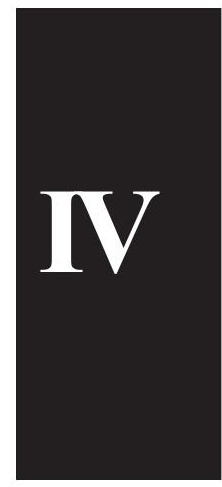


This article is removed. 
This article is removed. 